BANCA D'ITALIA

E U R O S I S T E M A

Temi di discussione

(Working Papers)

Rare disasters, the natural interest rate and monetary policy.

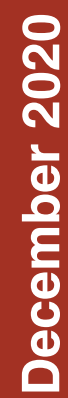

by Alessandro Cantelmo
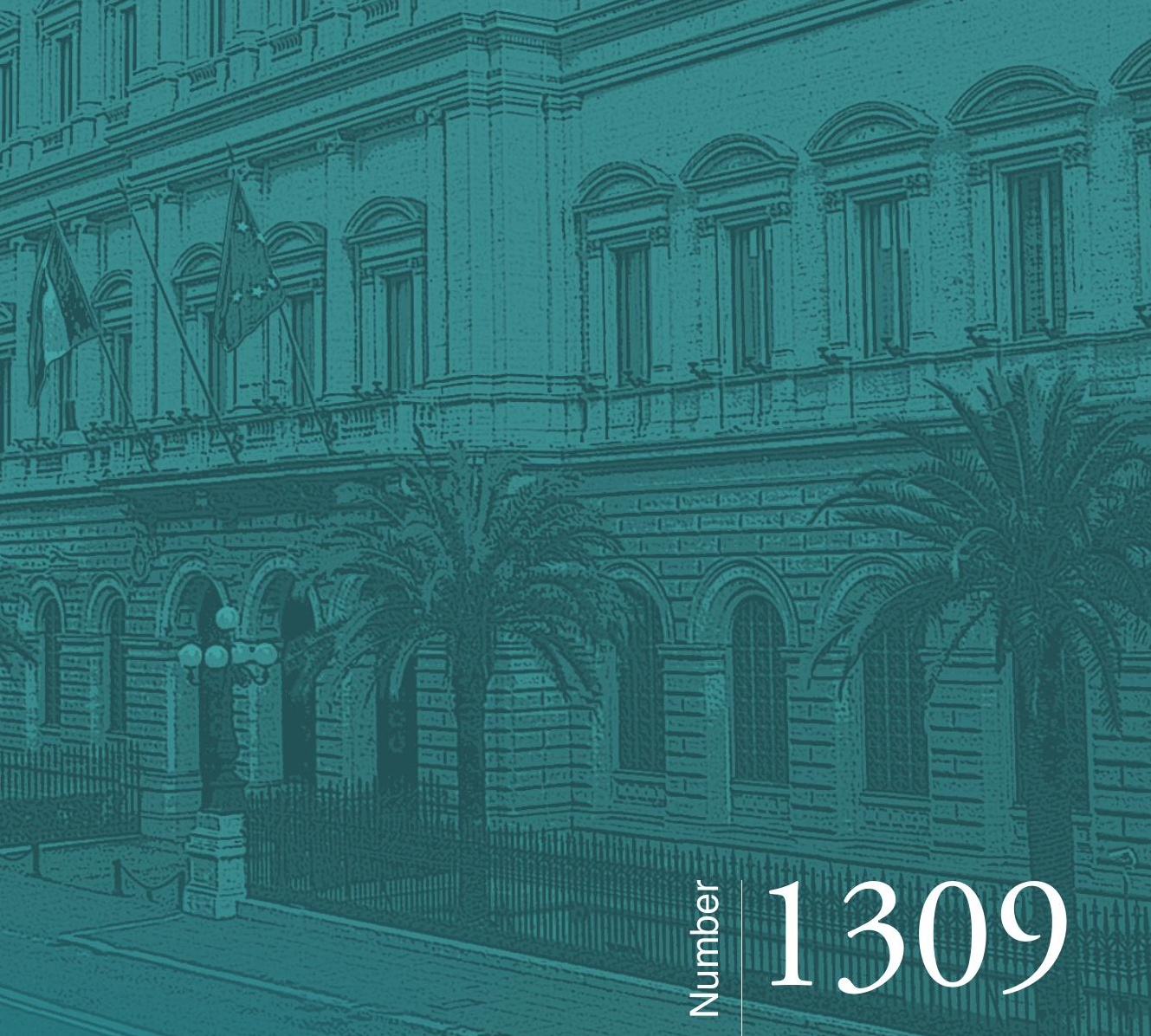



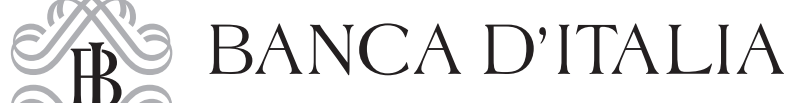

E U ROS I S T E M A

\section{Temi di discussione}

(Working Papers)

Rare disasters, the natural interest rate and monetary policy

by Alessandro Cantelmo

Number 1309 - December 2020 
The papers published in the Temi di discussione series describe preliminary results and are made available to the public to encourage discussion and elicit comments.

The views expressed in the articles are those of the authors and do not involve the responsibility of the Bank.

Editorial Board: Federico Cingano, Marianna Riggi, Monica Andini, Audinga Baltrunaite, Marco Bottone, Davide Delle Monache, Sara Formai, Francesco Franceschi, Adriana Grasso, Salvatore lo Bello, Juho Taneli Makinen, Luca Metelli, Marco Savegnago.

Editorial Assistants: Alessandra Giammarco, Roberto Marano.

ISSN 1594-7939 (print)

ISSN 2281-3950 (online)

Printed by the Printing and Publishing Division of the Bank of Italy 


\title{
RARE DISASTERS, THE NATURAL INTEREST RATE AND MONETARY POLICY
}

\author{
by Alessandro Cantelmo*
}

\begin{abstract}
This paper evaluates the impact of rare disasters on the natural interest rate and macroeconomic conditions by simulating a nonlinear New-Keynesian model. The model is calibrated using data on natural disasters in OECD countries. From an ex-ante perspective, disaster risk behaves as a negative demand shock and lowers the natural rate and inflation, even if disasters hit only the supply side of the economy. These effects become larger and nonlinear if extreme natural disasters become more frequent, a scenario compatible with climate change projections. From an ex-post perspective, a disaster realization leads to temporarily higher natural rate and inflation if supply-side effects prevail. If agents' risk aversion increases temporarily, disasters may generate larger demand effects and lead to a lower natural rate and inflation. If supply-side effects dominate, the central bank could mitigate output losses at the cost of temporarily higher inflation in the short run. Conversely, under strict inflation targeting, inflation is stabilized at the cost of larger output losses.
\end{abstract}

JEL Classification: E4, E5.

Keywords: natural disasters, natural interest rate, climate change, DSGE, monetary policy. DOI: $10.32057 / 0 . T D .2020 .1309$

\section{Contents}

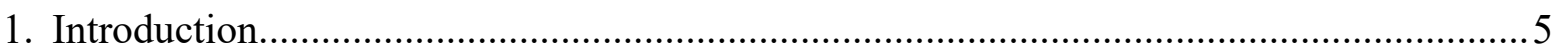

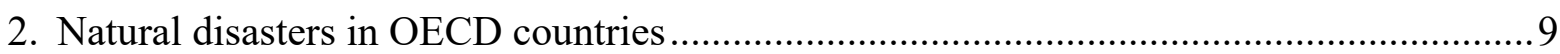

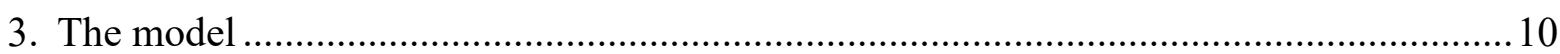

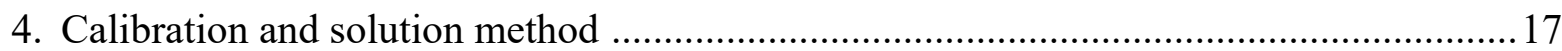

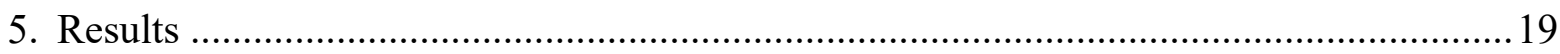

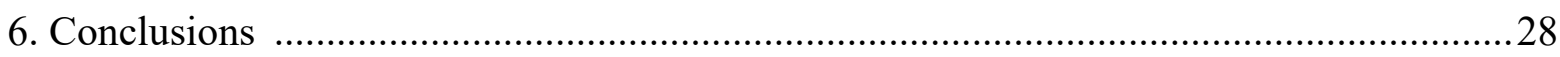

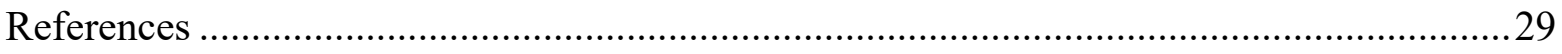

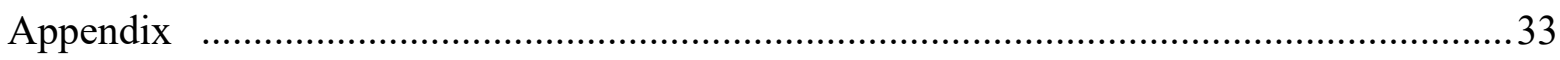

* Fellow at Banca d'Italia, Via Nazionale, 91 00184, Rome, Italy.

E-mail: alessandro.cantelmo@esterni.bancaditalia.it. 

"First, they [central banks] should incorporate climate risks in their assessment of potential growth and output as well as the natural equilibrium interest rate $\left(r^{*}\right) "$

Markus Brunnermeier and Jeann-Pierre Landau, VoxEu column. January 15, 2020.

\section{Introduction $^{1}$}

Policymakers and academics have been increasingly engaged in a lively debate about the short- and long-run macroeconomic effects of natural disasters. As far as advanced economies are concerned, these are events that have historically occurred with a low frequency but can have a large impact on GDP. ${ }^{2}$ Moreover, climate change is bound to make these events more frequent and powerful (see e.g. IPCC 2014; 2018; Alfieri et al., 2015; IMF, 2017). ${ }^{3}$ As regards the economic impact of natural disasters related to climate change, Burke et al. (2015), IMF (2017), Nordhaus (2019) and Cantelmo et al. (2019) provide evidence of large and nonlinear effects. ${ }^{4}$ However, it is still uncertain whether natural disasters entail prevalent demand- or supply-side effects whereby understanding which one prevails is paramount for the conduct of monetary policy. Focusing on the natural rate, defined as the interest rate compatible with stable prices and that equals savings and investment, helps unveiling which one prevails. ${ }^{5}$ Moreover, in the context of the new normal (Summers, 2014) with a persistently low natural rate, it is particularly important to understand its behavior in response to natural disasters. Indeed, since central banks would ideally set the policy rate to track it (Barsky et al., 2014), should downward pressures prevail, the effective lower bound on the policy rate might

\footnotetext{
${ }^{1}$ I thank Paolo Del Giovane, Stefano Neri, Fabio Busetti, Michele Caivano, and seminar participants at the Banca d'Italia for extremely valuable comments and suggestions. This paper has been developed during the Research Fellowship at Banca d'Italia. I am grateful to Massimiliano Pisani for his guidance on this project. The views expressed in this paper are those of the author and do not necessarily represent those of Banca d'Italia. All errors are mine.

${ }^{2}$ Section 2 provides evidence on natural disasters in OECD countries.

${ }^{3}$ In particular, Alfieri et al. (2015) estimate that river-floods are expected to double their frequency by 2035 in 21 of out of 37 countries in Europe, and further deteriorate in the rest of the century. Similarly, IMF (2017) estimate that most of natural disasters will more than double their frequency in advanced and emerging economies by 2100 , especially tropical cyclones and heat waves.

${ }^{4}$ For instance, Burke et al. (2015) estimate that once a country passes a threshold of $13^{\circ} \mathrm{C}$, it starts losing more than proportionally on its GDP as temperature increases. Moreover, Cantelmo et al. (2019) show that developing countries prone to natural disasters suffer much worse macroeconomic consequences than developing countries less exposed to them.

${ }^{5}$ Related to the recent Covid-19 shock, Guerrieri et al. (2020) investigate the response of the natural rate exactly for this purpose. The framework used here can be also applied to study the effects of the Covid-19 pandemic as well as its implications for the transmission of monetary policy.
} 
become more stringent. In the model, the natural rate is affected by natural disasters both ex-ante and ex-post. However, since it is not clear a-priori whether demand- or supply-side effects prevail, the natural rate might increases or decrease, depending on the responses of savings and investment to disaster risk and realizations. ${ }^{6}$ Likewise, inflation might increase or decrease, which might require different monetary policy responses.

This paper contributes to the ongoing debate on the macroeconomic effects of natural disasters using a nonlinear New-Keynesian (NK, henceforth) model, calibrated on OECD countries, under alternative assumptions on the monetary policy responses. We exploit data on the economic impact and frequency of natural disasters occurred in OECD countries to calibrate disaster shocks in the model. Those shocks are assumed to generate losses in physical capital and productivity thus directly impacting the supply-side of the economy, while demand-side effects of disaster realizations are obtained by assuming a temporarily higher risk aversion in the aftermath of disasters (as suggested by van den Berg et al. 2009; Cameron and Shah 2015; Cassar et al. 2017). Given the nonlinearities induced by disaster shocks, we solve the model with Taylor projection, an effective method to solve DSGE models with rare disasters (Fernández-Villaverde and Levintal, 2018). We then use the nonlinear model to simulate different scenarios and study the effects of natural disasters on the natural interest rate and inflation, and the monetary policy responses. Ex-ante, we evaluate the effects of disaster risk on the risky steady state of the natural interest rate and inflation, under alternative assumptions on the frequency and magnitude of natural disasters inspired by climate change studies. ${ }^{7}$ Ex-post, we simulate the responses of macroeconomic variables and monetary policy to disaster realizations.

The results are as follows. First, ex-ante, the risk of disaster realizations lowers the natural rate while making inflation fall short of the central bank's target. Although disasters originate from the supply-side of the economy, disaster risk behaves as a negative demand shock and induce an increase in precautionary savings. ${ }^{8}$ Moreover, these effects become larger and in a nonlinear way if extreme events become more frequent, as suggested by climate change scenarios. Second, ex-post, when disasters realize, if supply-side effects prevail, the natural rate and inflation are temporarily higher due to the destruction of physical capital and productivity loss. Indeed, investment becomes more profitable hence a higher interest rate

\footnotetext{
${ }^{6}$ The model does not account for the effective lower bound on the policy rate because of the solution method employed. See the discussion in Section 4.

${ }^{7}$ The risky steady state is the point where the economy converges after a long series of no disaster realizations. The risky steady state is determined by uncertainty about shocks realizations and differs from the deterministic one because agents take into account that shocks can occur, although they do not materialize.

${ }^{8}$ As explained by Gourio (2012), disaster risk generates uncertainty about productivity and capital depreciation hence risk-averse agents increase savings and decrease investment in risky capital.
} 
is required to stimulate saving, while the lower capital stock reduces supply thus increasing inflation. In contrast, if demand-side effects prevail because agents become temporarily more risk averse in the aftermath of disasters, both natural rate and inflation decrease and output losses are larger. Third, from a monetary policy perspective, if supply-side effects dominate, the central bank could reduce the output losses at the cost of temporarily higher inflation in the short run. Conversely, under strict inflation targeting, inflation is stabilized at the cost of larger output losses. This is not the case if demand-side effects dominate, whereby the central bank always decreases the policy rate.

Related literature. To the best of our knowledge, there exist only a few, mainly empirical, papers studying the monetary policy implications of natural disasters. However, their focus is ex-post, hence on the disaster realizations. Moreover, there is no assessment of the effects on the natural rate, neither ex-ante nor ex-post. The contribution of this paper is to fill this gap in the literature through a positive analysis of the ex-ante and ex-post effects of natural disasters on the natural rate and inflation. In doing so, we dissect the demand- and supply-side effects of natural disasters, since whether the former or the latter prevail is an open issue.

Rare disasters have been introduced in macroeconomic models (or as Gabaix, 2011, puts it: a "disasterization" of the model) in order to provide a unified framework with realistic macroeconomic and asset pricing properties. ${ }^{9}$ While disasters are typically modeled as rare large drops in the capital stock and productivity, disaster risk may arise from a time-varying probability (see Gabaix, 2012; Gourio, 2012; Isoré and Szczerbowicz, 2017) or a time-varying magnitude (Fernández-Villaverde and Levintal, 2018) of disasters. ${ }^{10}$

\footnotetext{
${ }^{9}$ Barro (2006) (and later Barro and Ursua 2008; 2012) revived this literature by constructing a detailed datasets on macroeconomic disasters (excluding natural disasters) to show that embedding them in an endowment economy helps solving the equity premium puzzle. Gabaix (2012) shows how introducing rare disasters in production economies helps solving several asset price puzzles. Gourio (2012) shows that disasters generate large drops in macroeconomic quantities and asset returns while a small increase in disaster probability suffices to generate a recession and countercyclical risk premia. Andreasen (2012) sets up a NK model where disasters hit only productivity and shows that, conditional on disaster realizations, the term premium is higher than in an economy without disasters. Gourio et al. (2013) shows that rare disasters help also reproducing stylized facts in international finance. Gourio et al. (2018) investigate whether a leaning against the wind policy is optimal to reduce the probability of recurring financial crises. Cantelmo et al. (2019) assess the combination of the ex-ante and the ex-post effects on the development path of small countries exposed to natural disasters using a calibrated small open economy RBC model and find much worse macroeconomic outcomes relative to developing countries less prone to natural disasters.

${ }^{10}$ Alternatively, the possibility of extreme events can be introduced by changing the distribution of standard business cycle shocks (Cúrdia et al., 2014; Kim and Ruge-Murcia, 2019). While there is no formal assessment of which modeling device is preferable, we decide to remain close to the larger body of literature surveyed here. Rare events might also reshape beliefs (Kozlowskiet al. 2018; 2020) or highlight that agents rationally choose to be inattentive to them thus taking bad actions when they realize (Mackowiak and Wiederholt, 2018).
} 
Isoré and Szczerbowicz (2017) set up a NK version of the RBC model of Gourio (2012) and show that disaster risk is essentially a negative demand shock, with falling inflation. Along these lines, Isoré (2018) shows that higher natural disaster risk in five Latin American countries can trigger a negative demand shock. However, they both focus only on the ex-ante effects of disasters and neglect the implications for the natural rate. ${ }^{11}$

Evidence on the ex-post effects of rare events on the natural rate is provided by Jorda et al. (2020). They compare its responses to large negative demand and supply shocks, such as pandemics and wars, respectively. Since the latter entail physical capital destruction, the natural rate is estimated to increase. However, they do not analyze natural disasters.

As regards the ex-post response of inflation to natural disasters, evidence is mixed. Parker (2018) and Klomp (2020) find a positive and significant response only to extreme events in advanced economies. Accordingly, Fratzscher et al. (2020) estimate only modest increases of inflation in countries adopting an inflation targeting regime, which are mainly advanced economies. Using evidence on the 2011 earthquake in Japan, Wieland (2019) shows how negative supply shocks are contractionary and inflationary at the zero-lower-bound.

Turning to the monetary policy responses, Keen and Pakko (2011) use a standard DSGE model to compute the optimal monetary policy response to a small natural disaster and conclude that it is optimal to raise the policy rate. ${ }^{12}$ Consistent with these theoretical results, Fratzscher et al. (2020) and Klomp (2020) estimate an increase in the policy rate to contain inflation in countries adopting inflation targeting. However, these findings seem to contrast with available evidence on the central banks' behavior in response to natural disasters. For instance, following the 2011 Christchurch earthquake, the Federal Reserve Bank of New Zealand (FRBNZ) lowered the policy rate by 50 basis points, while the Bank of Japan (BOJ), being the policy rate constrained by the effective lower bound, implemented liquidity measures to support economic activity in the aftermath of the 2011 earthquake. ${ }^{13}$

The remainder of the paper is organized as follows. Section 2 reports evidence on natural disasters in OECD countries. Section 3 describes the model, while Section 4 describes the calibration and the solution method. Section 5 presents the results and Section 6 concludes. The Appendix provides details on natural disasters in OECD countries (A), the stationary version of the model (B), the steady state (C), transmission mechanisms of disasters (D), sensitivity analysis (E) and an alternative channel of demand-side effects of disasters (F).

\footnotetext{
${ }^{11}$ Moreover, by neglecting the ex-post effects, they solve the model with perturbation methods which might miss the nonlinearities entailed by natural disasters.

${ }^{12}$ They calibrate the shock as Hurricane Katrina which caused damages of about $0.4 \%$ of U.S. GDP. Moreover, they solve the model with a second-order perturbation, which would miss much of the effects of a larger shock.

${ }^{13}$ See the FRBNZ March 2011 Monetary Policy Statement and the October 2011 BOJ's Reports and Research Papers.
} 


\section{Natural disasters in OECD countries}

Natural disasters in OECD countries characterize themselves as somewhat rare events with a large impact in terms of damages as a fraction of GDP. ${ }^{14}$ To construct evidence on natural disasters in OECD countries, we collected data since 1960 from the Emergency Events Database (EM-DAT), considering both climate-related natural disasters (droughts, extreme temperatures, floods, fog, landslides, storms and wildfires) and other events (earthquakes and volcanic activities). ${ }^{15}$ To obtain the fraction of GDP destroyed by natural disasters, we divide damages recorded in the EM-DAT (in USD million dollars) with the previous year nominal GDP (collected from the World Bank World Development Indicators, in USD million dollars). Then, we define a threshold of damages at $1 \%$ of GDP to select the sample of natural disasters: all those above the threshold are considered for constructing the distribution of natural disasters. ${ }^{16}$ Table 1 summarizes the statistics for natural disasters, while Table 4 in Appendix A reports the detailed list of events. Given our threshold on the damages to GDP, 45 events enter the sample, with an average annual probability of $2.2 \%$ and average loss to GDP equal to $2.95 \% .^{17}$

Figure 1 reports the empirical distribution (blue-bars) of damages as a fraction of GDP, along with theoretical distributions that will be discussed later. A few episodes are highlighted as an illustration. While the bulk of events caused rather limited damages to GDP, there are a number of disasters that had much larger impact. For instance, the extreme event

\footnotetext{
${ }^{14}$ The 36 OECD countries are: Australia, Austria, Belgium, Canada, Chile, Czech Republic, Denmark, Estonia, Finland, France, Germany, Greece, Hungary, Iceland, Ireland, Israel, Italy, Japan, Korea, Latvia, Lithuania, Luxembourg, Mexico, Netherlands, New Zealand, Norway, Poland, Portugal, Slovak Republic, Slovenia, Spain, Sweden, Switzerland, Turkey, United Kingdom, United States.

${ }^{15}$ EM-DAT: The Emergency Events Database - Universite Catholique de Louvain (UCL) - CRED, D. Guha-Sapir - www.emdat.be, Brussels, Belgium. The EM-DAT database is compiled from various sources including UN, governmental and non-governmental agencies, insurance companies, research institutes and press agencies. Natural disasters are recorded if they meet at least one of the following criteria: (a) 10 or more people reported killed; (b) 100 or more people reported affected; (c) declaration of a state of emergency; (d) call for international assistance. Economic damages cover both direct and indirect losses related to the disaster. They include the amount of damage to property, crops, and livestock. For each disaster, the registered figure corresponds to the damage value at the moment of the event. The choice of 1960 as the starting data is dictated by the availability of GDP series for all countries from the World Bank's World Development Indicators.

${ }^{16}$ In the literature on rare macroeconomic disasters, there are different ways to define a threshold to select the relevant events. In Barro (2006), disasters are defined as events in which, at the trough, GDP is at least $15 \%$ lower than at the pre-disaster peak and unfold over several years. Conversely, when considering natural disasters, events occur in one year and a fraction of GDP is destroyed within that year. It is thus reasonable to allow for a low threshold to select those events. In empirical studies of the effects of natural disasters on GDP growth (Fomby et al., 2013) and inflation (Parker, 2018), a similar approach is applied to select relevant events.

${ }^{17}$ The calculation of the annual probability of a disaster follows Barro (2006) and Barro and Ursua (2008; 2012). Details are provided in Appendix A. When more than one event occurred in the same year, the total damages are summed up.
} 
Table 1: Annual probabilities and damages to GDP from Natural Disasters (\%).

\begin{tabular}{c|ccccc}
\hline Annual probability & \multicolumn{5}{|c}{ Damages to GDP (\%) } \\
\hline & Mean & Min & Median & $97.5^{\text {th }}$ pctl & Max \\
\hline 2.20 & 2.95 & 1.00 & 2.04 & 11.8 & 17.4 \\
\hline
\end{tabular}

Sources: EM-DAT and authors' calculations. Annual probability is obtained by pooling all countries. Damages are expressed in percent of previous year's GDP.

at the $97.5^{\text {th }}$ percentile of the distribution destroyed almost $12 \%$ of GDP and essentially coincides with the impact of the 2011 earthquake in New Zealand. The largest event in the sample is the 2010 Chilean earthquake that caused damages by $17.4 \%$ of GDP. The average disaster caused almost a 3\% loss in GDP equal to the impact of the flood that hit Italy in 1966 and the volcanic eruption in Iceland in 1973, while another recent episode, namely the 2011 earthquake in Japan, places itself slightly above the average.

\section{The model}

We set up a NK model with stochastic trend growth and disaster shocks as in Gourio (2012), Isoré and Szczerbowicz (2017) and Fernández-Villaverde and Levintal (2018). The economy comprises a representative household supplying labor and deciding the optimal level of consumption and investment, while firms combine capital and labor to produce the single consumption good. Relative to a standard NK model, households feature EpsteinZin preferences (Epstein and Zin, 1989), while disaster shocks hit the capital stock and total factor productivity. Following Gourio (2012), we model total factor productivity as a combination of a permanent and a stationary component, both affected by disasters. ${ }^{18}$

\subsection{Disasters}

The modeling of disasters closely follows Fernández-Villaverde and Levintal (2018). Private investment is subject to adjustment costs (see next subsection for a detailed description), with the law of motion of capital being:

$$
k_{t}^{*}=(1-\delta) k_{t}+\left(1-S\left[\frac{x_{t}}{x_{t-1}}\right]\right) x_{t},
$$

\footnotetext{
${ }^{18}$ Conversely, in Isoré and Szczerbowicz (2017) and Fernández-Villaverde and Levintal (2018) TFP is only permanent.
} 
Figure 1: Empirical and theoretical distributions of damages as a fraction of GDP.

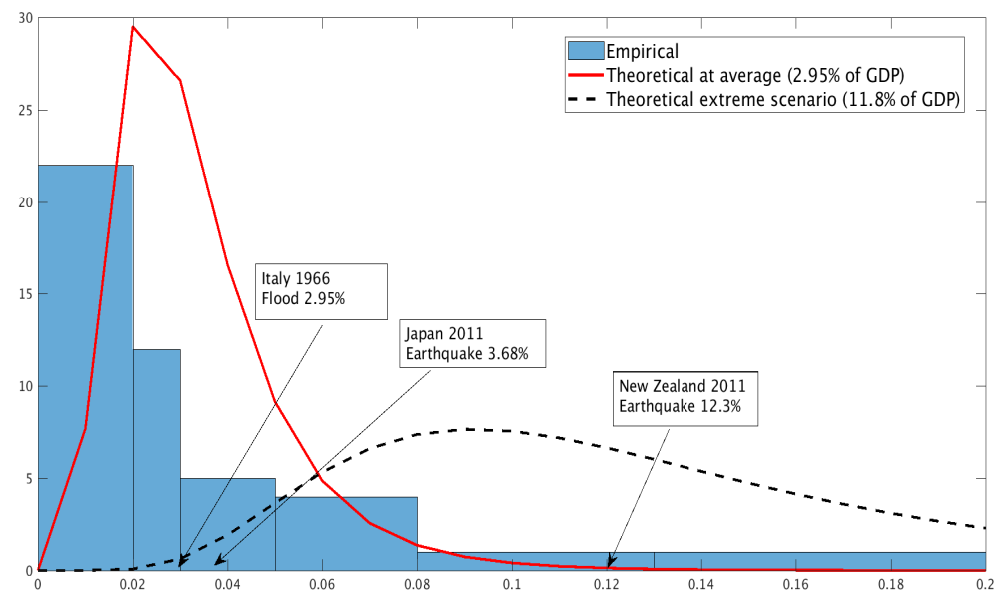

Notes: Distribution of damages as a fraction of GDP. Blue bars: empirical distribution from EM-DAT and authors' calculations. Red-solid line: theoretical distribution with average damages to GDP as in the data (2.95\% of GDP). Black-dashed line: theoretical distribution depicting an extreme scenario with average damages to GDP equal to $11.8 \%$ of GDP.

where $k_{t-1}^{*}$ is the optimal choice of capital at time $t-1$, whereas the actual capital stock $k_{t}$ is the optimally chosen net of disasters:

$$
k_{t}=k_{t-1}^{*} e^{-d_{t} \theta_{t}} .
$$

The dummy variable $d_{t}$ takes a value of 1 with probability $p_{d}$ in case of disaster and 0 with probability $\left(1-p_{d}\right)$ otherwise. When a disaster occurs, the capital stock falls by $\theta_{t}$, which is time-varying:

$$
\log \theta_{t}=\left(1-\rho_{\theta}\right) \log \bar{\theta}+\rho_{\theta} \log \theta_{t-1}+\sigma_{\theta} \epsilon_{\theta, t},
$$

where the random variable $\theta_{t}$ takes a log-normal distribution with average disaster size $\bar{\theta}$ and stochastic volatility $\sigma_{\theta} \epsilon_{\theta, t} \cdot{ }^{19}$ It is important to note that a disaster realization is a one-off event, i.e. it occurs only in one quarter (when $d_{t}=1$ ). Conversely, disaster risk is persistent: following Fernández-Villaverde and Levintal (2018), equation (3) can be interpreted as a disaster risk shock meaning that agents might temporarily expect the average disaster size $\bar{\theta}$ to be higher, with $\rho_{\theta}$ governing the persistence of the risk shock. ${ }^{20}$

\footnotetext{
${ }^{19}$ Therefore: $\log \theta_{t} \sim N\left(\log \bar{\theta} ; \frac{\sigma_{\theta}^{2}}{1-\rho_{\theta}^{2}}\right)$.

${ }^{20}$ Gourio (2012) and Isoré and Szczerbowicz (2017) allow for a time-varying probability of disasters hence disaster risk entails its temporary increase. Conversely, we follow Fernández-Villaverde and Levintal (2018) by assuming a fixed probability with a time-varying impact of the disaster hence disaster risk entails a temporary increase in the average magnitude of disasters. Nevertheless, the effects of a disaster risk shock is similar between the two modeling choices.
} 
In addition to destroying part of the capital stock, disaster shocks affect also total factor productivity. Following Gourio (2012), aggregate TFP $\left(A_{t}^{\mathrm{agg}}\right)$ has both a permanent $\left(A_{t}\right)$ and a stationary $\left(A_{t}^{T}\right)$ component. The former is defined as a random walk with a drift while the latter follows a $\mathrm{AR}(1)$ process. The equations governing the TFP processes are:

$$
\begin{aligned}
\log A_{t}^{\operatorname{agg}} & =\log A_{t}+\log A_{t}^{T}, \\
\log A_{t} & =\log A_{t-1}+\Lambda_{A}+\sigma_{A} \epsilon_{A, t}-\omega(1-\alpha) d_{t} \theta_{t}, \\
\log A_{t}^{T} & =\rho_{a} \log A_{t-1}^{T}-(1-\omega)(1-\alpha) d_{t} \theta_{t},
\end{aligned}
$$

where $\Lambda_{A}$ is the steady-state TFP growth, $\sigma_{A} \epsilon_{A, t}$ is the Gaussian component of permanent TFP. Similarly to Gourio (2012), disasters affect the two components of TFP differently, where parameter $\omega \in[0,1]$ governs the relative impact. ${ }^{21}$ Whenever $0<\omega<1$, this mechanism generates a fall in TFP followed by a partial recovery, i.e. disasters temporarily affect TFP which then converges to its long run impact. Since there is no agreement on the effects of natural disasters on productivity, we will explore different values of $\omega$. The extreme cases of $\omega=0$ and $\omega=1$ imply that disasters have only a temporary or a permanent effect, respectively. Hsiang and Jina (2014) estimate that tropical cyclones have a highly persistent effect on the growth rate and reject hypothesis of "creative destruction" or "buildback better". With a focus on other types of disasters, Nakamura et al. (2013) show that disasters are followed by partial recoveries, hence with a temporary higher growth rate of output after the disaster relative to the pre-disaster growth rate. By appealing to this evidence, we will assume that natural disasters have both short- and long-run impact on productivity hence the aftermath of disasters is characterized by temporarily faster growth and a partial recovery. We then also explore the two extreme cases of $\omega=0$ and $\omega=1$. Finally, disaster variables in the two processes of TFP are rescaled by $(1-\alpha)$ to ensure that capital and output fall by the same amount.

\subsection{Households}

The representative household's utility reads as:

$$
V_{t}^{1-\psi}=U_{t}^{1-\psi}+\beta E_{t}\left(V_{t+1}^{1-\gamma}\right)^{\frac{1-\psi}{1-\gamma}},
$$

\footnotetext{
${ }^{21}$ Gourio (2012) employes a more general specification, whereby the two components of TFP are subject to two different shocks when in a disaster state. This nevertheless implies that disasters have a different relative effect on permanent and temporary TFP.
} 
where the period- $t$ utility $U_{t}$ is defined over consumption $c_{t}$ and labor $l_{t}, U_{t}=e^{\xi_{t}} c_{t}\left(1-l_{t}\right)^{\nu}$, while $V_{t+1}$ is its continuation value and $\xi_{t}$ is an inter-temporal preference shock. Parameter $\gamma$ governs risk aversion while $1 / \hat{\psi}$ is the inter-temporal elasticity of substitution, where $\hat{\psi}=1-(1+\nu)(1-\psi)$ is its inverse. As noted by Caldara et al. (2012), the importance of recursive preferences is twofold. First, they allow for a distinction between $\gamma$ and $\hat{\psi}^{22}$ Second, they imply a trade-off between current and a certainty equivalent of future utility. Households therefore have preference for early $(\gamma>\hat{\psi})$ or later $(\gamma<\hat{\psi})$ resolution of uncertainty. These features are particularly appealing in our context where agents face the risk of natural disasters, which induces precautionary savings captured by the recursive structure of preferences.

Each period, the household's budget constraint (in real terms) reads as:

$$
c_{t}+x_{t}+b_{t+1}=w_{t} l_{t}+r_{t} k_{t}+R_{t-1} b_{t}+F_{t}+T_{t}
$$

where $x_{t}$ denotes investment in capital, $w_{t}$ is the real wage, $r_{t}$ is the rental rate on capital $k_{t}, F_{t}$ are profits earned from firms, $T_{t}$ is a lump-sum transfer from the government and $b_{t}$ represents private bonds which pay a gross return $R_{t}$.

The household determines the optimal capital stock, $k_{t}^{*}$, which depreciates at a rate $\delta$, and the investment $x_{t}$ needed to achieve it. However, changing investment plans entails a quadratic cost $S\left[\frac{x_{t}}{x_{t-1}}\right]=\frac{\kappa}{2}\left(\frac{x_{t}}{x_{t-1}} \hat{z}_{t}-\hat{z}\right)^{2}$ as in Christiano et al. (2005), where $\hat{z}_{t}=\left(\frac{A_{t}}{A_{t-1}}\right)^{\frac{1}{1-\alpha}}$ is the technological stochastic trend growth.

Optimal choices of consumption, financial assets, labor supply, capital stock and investment are taken to maximize utility (7) subject to (8), and (1) thus leading to the following first-order conditions:

$$
\begin{aligned}
1 & =E_{t}\left[M_{t+1} \frac{R_{t}}{\Pi_{t+1}}\right] \\
w_{t} & =\nu \frac{c_{t}}{1-l_{t}}, \\
q_{t} & =E_{t}\left(M_{t+1} e^{-d_{t+1} \theta_{t+1}}\left[r_{t+1}+q_{t+1}(1-\delta)\right]\right), \\
1 & =q_{t}\left[1-S\left[\frac{x_{t}}{x_{t-1}}\right]-S^{\prime}\left[\frac{x_{t}}{x_{t-1}}\right] \frac{x_{t}}{x_{t-1}}\right]+ \\
& +E_{t} M_{t+1} q_{t+1} S^{\prime}\left[\frac{x_{t+1}}{x_{t}}\right]\left(\frac{x_{t+1}}{x_{t}}\right)^{2} .
\end{aligned}
$$

Equation (9) is a standard Euler Equation of consumption, where $M_{t+1} \equiv \beta \frac{\lambda_{t+1}}{\lambda_{t}} \frac{V_{t+1}^{\psi-\gamma}}{E_{t}\left(V_{t+1}^{1-\gamma}\right)^{\frac{\psi-\gamma}{1-\gamma}}}$

\footnotetext{
${ }^{22}$ The more standard case of expected utility can be achieved by setting $\gamma=\hat{\psi}$.
} 
is the stochastic discount factor with Epstein-Zin preferences, where $\lambda_{t}$ is the Lagrange multiplier on the budget constraint (8). Equation (10) represents the marginal rate of substitution between consumption and leisure, while equations (11) and (12) define the asset price and investment decisions, respectively.

\subsection{Firms}

The firms' side of the model is completely standard and borrowed from Fernández-Villaverde and Levintal (2018). Perfectly competitive final good producers combine $i$ intermediate goods according to

$$
y_{t}=\left(\int_{0}^{1} y_{i, t}^{\frac{\epsilon-1}{\epsilon}}\right)^{\frac{\epsilon}{\epsilon-1}}
$$

where $\epsilon$ is the elasticity of substitution. Intermediate goods producers combine labor and capital according to a Cobb-Douglas production function:

$$
y_{i, t}=A_{t}^{\mathrm{agg}} k_{i, t}^{\alpha} l_{i, t}^{1-\alpha}
$$

where $\alpha \in[0,1]$ is the capital share of income. Intermediate firms choose inputs and prices to maximize profits $F_{i, t}=y_{i, t}-w_{i, t} l_{i, t}-r_{i, t} k_{i, t}$ subject to the production function (14) and a Dixit-Stiglitz demand function $y_{i, t}=\left(\frac{P_{i, t}}{P_{t}}\right)^{-\epsilon} y_{t}$ and are subject to Calvo price stickiness. At the symmetric equilibrium all $i$ firms are equal hence the first-order conditions read as:

$$
\begin{aligned}
g_{t}^{1} & =m c_{t} y_{t}+\theta_{p} E_{t} M_{t+1}\left(\frac{\Pi_{t}^{\chi}}{\Pi_{t+1}}\right)^{-\epsilon} g_{t+1}^{1}, \\
g_{t}^{2} & =\Pi_{t}^{*} y_{t}+\theta_{p} E_{t} M_{t+1}\left(\frac{\Pi_{t}^{\chi}}{\Pi_{t+1}}\right)^{1-\epsilon}\left(\frac{\Pi_{t}^{*}}{\Pi_{t+1}^{*}}\right) g_{t+1}^{2}, \\
\epsilon g_{t}^{1} & =(\epsilon-1) g_{t}^{2}, \\
1 & =\theta_{p}\left(\frac{\Pi_{t-1}^{\chi}}{\Pi_{t}}\right)^{1-\epsilon}+\left(1-\theta_{p}\right)\left(\Pi_{t}^{*}\right)^{1-\epsilon} \\
m c_{t} & =\left(\frac{1}{1-\alpha}\right)^{1-\alpha}\left(\frac{1}{\alpha}\right)^{\alpha} \frac{w^{1-\alpha} r_{t}^{\alpha}}{A_{t}^{\mathrm{agg}}} \\
\frac{k_{t}}{l_{t}} & =\frac{\alpha}{1-\alpha} \frac{w}{r_{t}}, \\
v_{t}^{p} & =\theta_{p}\left(\frac{\Pi_{t-1}^{\chi}}{\Pi_{t}}\right)^{1-\epsilon} v_{t-1}^{p}+\left(1-\theta_{p}\right)\left(\Pi_{t}^{*}\right)^{1-\epsilon},
\end{aligned}
$$


where $\theta_{p} \in[0,1]$ denotes the per-period probability of not resetting the price, while $\chi \in[0,1]$ governs the degree of indexation to past inflation, $\Pi_{t}=\frac{p_{t}}{p_{t-1}}$ is the gross inflation rate, $\Pi_{t}^{*}=\frac{p_{t}^{*}}{p_{t}}$ is the ratio of the optimal reset price and the price of the final good, $m c_{t}$ is the marginal cost, $g^{1}$ and $g^{2}$ are auxiliary variables, and finally $v_{t}^{p}$ denotes price dispersion.

\subsection{Monetary Policy}

As in Fernández-Villaverde and Levintal (2018) the central bank sets the interest rate according to the following rule:

$$
\frac{R_{t}}{R}=\left(\frac{R_{t-1}}{R}\right)^{\gamma_{R}}\left(\left(\frac{\Pi_{t}}{\bar{\Pi}}\right)^{\gamma_{\Pi}}\left(\frac{\frac{y_{t}}{y_{t-1}}}{\exp \left(\Lambda_{y}\right)}\right)^{\gamma_{y}}\right)^{1-\gamma_{R}} e^{m_{t}}
$$

where $\gamma_{R} \in[0,1]$ is the interest rate inertia , $\gamma_{\Pi}>0$ is the responsiveness to deviation of inflation from the target $\bar{\Pi}$, and $\gamma_{y}$ governs the response to output growth, where $\Lambda_{y}$ denotes the growth rate of output along the balanced growth path. Finally, $e^{m_{t}}$ is a mean zero normally distributed monetary innovation.

In addition to this standard interest rate rule, we also allow the central bank to directly react to disasters, as in Keen and Pakko (2011). This disaster-Taylor rule is also in the same spirit of Hills et al. (2019) who augment a standard Taylor rule to specifically account for the risk of hitting the effective lower bound. ${ }^{23}$ The Taylor rule is therefore augmented as follows

$$
\frac{R_{t}}{R}=\left(\frac{R_{t-1}}{R}\right)^{\gamma_{R}}\left(\left(\frac{\Pi_{t}}{\bar{\Pi}}\right)^{\gamma_{\Pi}}\left(\frac{\frac{y_{t}}{y_{t-1}}}{\exp \left(\Lambda_{y}\right)}\right)^{\gamma_{y}}\left(\exp \left(-\frac{d_{t} \theta_{t}}{d \theta}\right)^{\gamma_{D}}\right)\right)^{1-\gamma_{R}} e^{m_{t}}
$$

where $\gamma_{D}>0$ governs the reaction to the disaster. This rule implies that, when a disaster realizes (e.g. $d_{t}=1$ ), the central bank adjusts the policy rate according to the size of the disaster, in addition to inflation and output growth.

\subsection{Aggregation}

In equilibrium all markets clear hence the aggregate resource constraint reads as:

$$
y_{t}=c_{t}+x_{t}
$$

\footnotetext{
${ }^{23}$ However, Hills et al. (2019) modify the intercept of the Taylor rule by changing the interest rate in steady state.
} 


\subsection{The natural rate of interest}

Following Del Negro et al. (2017) and Neri and Gerali (2017), we define the natural interest rate as the risk-free rate that prevails in a counterfactual economy without nominal rigidities. In the flexible price model, the Euler equation contains the natural rate:

$$
1=E_{t} M_{t+1}^{f} R_{t}^{n}
$$

where $M_{t+1}^{f}$ is stochastic discount factor. When the system is detrended (see Appendix B for more details), it reads as:

$$
M_{t+1}^{f}=\beta \frac{\tilde{\lambda}_{t+1}^{f}}{\tilde{\lambda}_{t}^{f}}\left(\hat{z}_{t+1}\right)^{-\psi} \frac{\left(\tilde{V}_{t+1}^{f} / \tilde{V}^{f, s s}\right)^{\psi-\gamma}\left(\hat{z}_{t+1}\right)^{\psi-\gamma}}{E_{t}\left(\left(\tilde{V}_{t+1}^{f} / \tilde{V}^{f, s s}\right)^{1-\gamma}\left(\hat{z}_{t+1}\right)^{1-\gamma}\right)^{\frac{\psi-\gamma}{1-\gamma}}},
$$

where variables with a superscript $f$ are detrended, variables with $\mathrm{a} \ll \sim \gg$ are detrended, and $\hat{z}_{t}=\frac{z_{t}}{z_{t-1}}$ is the growth rate of productivity. Fernández-Villaverde and Levintal (2018), following the literature on asset prices (see e.g. Lucas, 1978; Lettau, 2003; Gourio, 2012; van Binsbergen et al., 2012; Nakamura et al., 2013; Isoré and Szczerbowicz, 2017), show that the price of a one-period risk-free bond can be defined as:

$$
q_{t}^{f}=E_{t} M_{t+1}^{f}
$$

It follows that the risk free rate can be calculated as its inverse. With a single (risk-free) bond in the economy, the natural rate coincides with the risk-free rate in the flexible-price economy, hence we can define

$$
R_{t}^{n}=\frac{1}{q_{t}^{f}}=\left(E_{t} M_{t+1}^{f}\right)^{-1}
$$

From the household's first order condition, we know that $\frac{\tilde{\lambda}_{t+1}^{f}}{\tilde{\lambda}_{t}^{f}}=\left(\frac{\tilde{c}_{t+1}^{f}}{\tilde{c}_{t}^{f}}\right)^{-\psi}\left(\frac{1-l_{t+1}^{f}}{1-l_{t}^{f}}\right)^{\nu(1-\psi)}$ , which means that, as shown by Del Negro et al. (2017) and Neri and Gerali (2017), the natural rate depends on consumption growth and the growth in hours worked. However, there are two departures from the natural rate in standard models. First, it depends on the disasters through the technological growth rate. Second, there is an additional term due to the recursive preferences that captures the effects of uncertainty. 


\section{Calibration and solution method}

Table 2 reports the calibration at a quarterly frequency. The calibration is disciplined either by data or by the literature, with a few departures, discussed in details. To calibrate the disasters, we use data on OECD countries on natural disasters reported in Section 2. The annual probability is set at $2.2 \%$ while the average loss in GDP is $2.95 \%$. Given the average GDP $\operatorname{loss}(\log \bar{\theta})$, the persistence of disaster risk $\left(\rho_{\theta}\right)$ and its standard deviation $\left(\sigma_{\theta}\right)$ are calibrated to obtain a theoretical distribution of damages as close as possible to the observed one. In particular, we adjust these two parameters to match the first two moments of the empirical distribution. The red line in Figure 1 reports the theoretical distribution using the average GDP loss of $2.95 \%$ (red line) and also a distribution in which the average GDP loss is increased to $11.8 \%$ (the $97.5^{\text {th }}$ percentile in the data, black-dashed line), while keeping the same standard deviation $\left(\sigma_{\theta}\right)$. This scenario will be discussed in Section $5{ }^{24}$ Two other parameters are important for the effects of natural disasters. First, we assume that the shock distributes equally between the permanent and stationary components of TFP, e.g. $\omega=0.50$. As discussed in Section 3.1, this implies a temporary higher growth rate after the disaster and a partial recovery. In addition, we set the autoregressive parameter of temporary TFP at $\rho_{a}=0.1 .^{25}$

For the remaining parameters, we consider the euro area to be the core of OECD countries and calibrate them accordingly. ${ }^{26}$ Therefore, most of the parameters are set according to the estimates of Smets and Wouters $(2003 ; 2005)$ and Coenen et al. (2018) for the euro area, including the shock processes. The scaling parameter on the disutility of labor $(\nu)$ is set to get hours worked of $1 / 3$ in the deterministic steady state. Risk aversion $(\gamma)$ is set to obtain a natural rate in the risky steady state in line with the estimates of Holston et al. (2017) and Neri and Gerali (2017), while the inter-temporal elasticity of substitution $(\hat{\psi})$ is calibrated as in Gourio (2012) and Fernández-Villaverde and Levintal (2018). ${ }^{27}$

Finally, following Coenen et al. (2018), the trend growth rate of technology $\Lambda_{A}$ is such that the annual GDP growth rate is $1.5 \%$, while the discount factor $(\beta)$ is set such that the

\footnotetext{
${ }^{24}$ It is important to note that while these are the distributions of damages as a fraction of GDP, the disaster probability determines how often there is a random draw from them.

${ }^{25}$ Sensitivity on this parameter reveals no significant changes in the results.

${ }^{26}$ Parameters are nevertheless quite similar between EA and US, as e.g. estimated by Smets and Wouters (2005) and Villa (2016).

${ }^{27}$ Risk aversion is usually calibrated to match a measure of risk premium. As first shown by Barro (2006), followed by Gourio (2012), Nakamura et al. (2013), and Fernández-Villaverde and Levintal (2018), among others, the combination of EZ preferences and rare disasters allows to match risk premia without relying on extremely high values of risk aversion. However, in those papers, disasters on average cause GDP losses in the range $22 \%-40 \%$, hence are much larger than the average natural disaster size we calibrate. We therefore need a slightly higher value of $\gamma$ to match the risk-free rate.
} 
Table 2: Calibrated parameters.

\begin{tabular}{llll}
\hline Parameter & & Value & Source/target \\
\hline Disaster probability & $p_{d}$ & 0.0055 & EMDAT \\
Mean disaster size & $\bar{\theta}$ & 0.0299 & EMDAT \\
Persistence of disaster risk shock & $\rho_{\theta}$ & 0.95 & Damages distribution \\
Std. of disaster risk shock & $\sigma_{\theta}$ & 0.22 & Damages distribution \\
Weight of disasters on permanent TFP & $\omega$ & 0.50 & Tentative \\
Persistence of stationary TFP & $\rho_{a}$ & 0.10 & Tentative \\
Leisure preference & $\nu$ & 1.55 & $L=0.33$ \\
Risk aversion & $\gamma$ & 7 & $R_{R S S}^{n} \approx 1.6 \%$ \\
Inverse IES & $\hat{\psi}$ & 0.5 & Gourio (2012) \\
Trend growth of technology & $\Lambda_{A}$ & 0.0026 & Coenen et al. (2018) \\
Discount factor & $\beta$ & 0.999 & Coenen et al. (2018) \\
Capital share of income & $\alpha$ & 0.30 & Smets and Wouters (2003) \\
Capital depreciation rate & $\delta$ & 0.025 & FVL \\
Investment adjustment cost parameter & $\kappa$ & 6.92 & Smets and Wouters (2003) \\
Calvo price stickiness parameter & $\theta_{p}$ & 0.905 & Smets and Wouters (2003) \\
Automatic price adjustment & $\chi$ & 0.472 & Smets and Wouters (2003) \\
Elasticity of substitution & $\epsilon$ & 6 & Villa (2016) \\
Inflation target & $\bar{\Pi}$ & 1.0047 & Coenen et al. (2018) \\
Inflation parameter in Taylor rule & $\gamma_{\Pi}$ & 1.69 & Smets and Wouters (2003) \\
Output growth parameter in Taylor rule & $\gamma_{y}$ & 0.095 & Smets and Wouters (2003) \\
Interest rate smoothness in Taylor rule & $\gamma_{R}$ & 0.95 & Smets and Wouters (2003) \\
Std. of productivity shock & $\sigma_{A}$ & 0.0062 & Smets and Wouters (2003) \\
Std. of preference shock & $\sigma_{\xi}$ & 0.0039 & Smets and Wouters (2003) \\
Std. of monetary policy shock & $\sigma_{m}$ & 0.0010 & Smets and Wouters (2003) \\
\hline
\end{tabular}

annualized net real rate in the is almost $2 \%$ in the deterministic steady state. Prices are set to last on average 10 quarters. The remaining parameters are pretty standard and for some of them we will experiment alternative values, as discussed in Appendix E.

To simulate the model, we resort to Taylor projection, a recently developed solution method proposed by Levintal (2018) and Fernández-Villaverde and Levintal (2018) to solve DSGE models with rare disasters. Fernández-Villaverde and Levintal (2018) demonstrate that a Taylor projection up to third order is more accurate and generally faster to compute than perturbation methods up to a fifth order of approximation and projection methods (Smolyak collocation) up to a third order to solve a wide range of DSGE models with rare disasters. Taylor projection essentially combines the setup of standard projection methods with approximation methods via Taylor expansions. There are essentially four steps to compute the solution. The first two are standard in projection methods, while the last two use Taylor approximations. In particular: i) approximate the policy function with a 
$n$-order polynomial; ii) construct a residual function which depends on the state variables and unknown coefficients; iii) rather than using a grid to find the coefficients that make the residual function zero (as in standard projection methods), take a $n$-order Taylor expansion of the residual function at a particular point of the state-space; iv) find the coefficients that make the resulting Taylor series zero. The method hence yields a solution that, although not global, is possible to approximate at many points of the state-space, and this makes it accurate in dealing with large nonlinearities. The main limitations of this method are that the solution is not global and cannot account for occasionally binding constraints. Moreover, the number of state variables allowed to find an accurate solution is quite limited. In the simulations below we use a third order Taylor projection where the residual function is approximated around the stochastic steady state.

\section{Results}

\subsection{Ex-ante: disaster risk}

This section shows the effects of disaster risk on the natural interest rate and inflation under different interest rate rules and calibration of disasters by computing the risky steady states of the natural rate and inflation. Following Coeurdacier et al. (2011) and Hills et al. (2019), the risky steady state is defined as the steady state at which variables converge after a long series of zero realizations of shocks. Differently from the deterministic steady state, agents are aware that shocks can occur therefore uncertainty affects their optimal decisions despite the fact that no actual shock realizes. ${ }^{28}$

Three natural disaster scenarios are simulated. The top panel of Table 3 shows results from the baseline calibration, where the average natural disaster is considered (scenario (i) labelled average disaster). The remaining panels show results when an extreme event is considered. Following Fratzscher et al. (2020), we select the $97.5^{\text {th }}$ percentile of the distribution of damages to GDP. This disaster destroys 11.8\% of GDP (roughly the impact of the 2011 earthquake in New Zealand), but it is extremely rare since, in the data, it's annual probability is $0.05 \%$ (scenario (ii) labelled extreme disaster). Finally, the bottom panel shows what happens when the extreme event becomes more frequent, a scenario foreseen by many climate change studies as discussed in Section 1 (scenario (iii) labelled extreme disaster worst scenario). Effectively, the extreme disaster scenarios entail a shift of the distribution of damages, e.g. a change in the first moment $(\bar{\theta})$ from 0.0299 to 0.1256 , as depicted by the

\footnotetext{
${ }^{28}$ As in Fernández-Villaverde and Levintal (2018), the risky steady state is calculated by simulating the model for 100 periods without shocks.
} 
Table 3: Risky steady state under different distributions of disasters and monetary policy regimes.

\begin{tabular}{|c|c|c|c|c|}
\hline & \multicolumn{4}{|c|}{ Risky Steady State } \\
\hline & No disasters & Standard Taylor Rule & Inflation Targeting & Disaster Taylor Rule \\
\hline \multicolumn{5}{|c|}{ (i) Average disaster ( $p_{d}^{a n n}=2.2 \%$; Average damages to $G D P=2.95 \%$ ) } \\
\hline Natural rate & 1.61 & 1.55 & 1.55 & 1.55 \\
\hline Inflation & 1.88 & 1.85 & 1.88 & 1.88 \\
\hline \multicolumn{5}{|c|}{ (ii) Extreme disaster ( $p_{d}^{a n n}=0.05 \%$; Average damages to $G D P=11.8 \%$ ) } \\
\hline Natural rate & 1.61 & 1.60 & 1.60 & 1.60 \\
\hline Inflation & 1.88 & 1.87 & 1.88 & 1.88 \\
\hline \multicolumn{5}{|c|}{ (iii) Extreme disaster - worst scenario ( $p_{d}^{a n n}=2.2 \%$; Average damages to $G D P=11.8 \%$ ) } \\
\hline Natural rate & 1.61 & 1.26 & 1.26 & 1.26 \\
\hline Inflation & 1.88 & 1.48 & 1.87 & 1.71 \\
\hline
\end{tabular}

Notes: Risky steady state of the natural rate and inflation under three alternative distribution of disaster shocks (panels (i) to (iii)) and three monetary policy rules (second to fourth columns). The first column reports the risky steady state of an economy without disasters. The risky steady state is calculated by simulating the model for 100 periods without shocks. Inflation and interest rates are in $\%$ annualized values. The central bank's inflation target is $1.9 \%$.

black-dashed line in Figure 1.

As regards the interest rate rules, in the baseline case the central bank follows the standard Taylor rule (22). Then two alternative monetary policy regimes are studied. First, we study an inflation targeting regime by setting the reaction parameter of the standard Taylor rule $(22)$ to inflation to a very large value, i.e. $\gamma_{\Pi}=25$. Then, we set a disaster Taylor rule according to equation (23) with a strong direct response to disasters, $\gamma_{D}=0.30$, several times larger than the response to output growth. Crucially, interest rate rules affect the second moments of variables hence the risky steady state.

The first column of Table 3 reports the risky steady state values in an economy without disaster risk, hence subject only to the other business cycle shocks. These have very little effect on the economy, with the implied natural rate close to the estimates of Barsky et al. (2014) and Neri and Gerali (2017) and inflation virtually at target. Under the average disaster scenario (i), when the economy is potentially hit by disasters and monetary policy is set according to a standard interest rate rule (second column), at the risky steady state, the natural rate is 6 basis points lower due to precautionary savings, while inflation falls short of target by 5 basis points. Conversely, both the alternative Taylor rules (third and fourth columns) are able to keep inflation close to target, although for different reasons. ${ }^{29}$ Indeed, while under inflation targeting the central bank stabilizes inflation in all states, the

\footnotetext{
${ }^{29}$ Note that changing parameters in the Taylor rule does not affect the natural rate since, by definition, monetary policy is neutral in the flexible-price equilibrium.
} 
disaster Taylor rule stabilizes more output hence agents anticipate it and save less ex-ante and inflation is higher. Nevertheless, the impact of the average natural disaster on the risky steady state of the natural rate and inflation is rather limited. This holds also for under the extreme disaster scenario (ii). It is hence possible to infer that, given their past frequency and size, the effect of natural disasters risk on the natural rate and inflation has been small. However, rather than taking an historical perspective, it is interesting to design a future scenario in which extreme events become more frequent, as climate change studies suggest, and evaluate the ex-ante effects on the natural interest rate and inflation. ${ }^{30}$ Results under this scenario are reported in the bottom panel (iii) of Table 3. Under a standard Taylor rule, the natural interest rate settles at 1.26\%, 35 basis points lower than in the economy not subject to disaster risk. Inflation falls short of the central bank's target and it is 40 basis points lower than without disasters. Therefore, ex-ante effects of natural disasters become more relevant as the frequency and/or magnitude of natural disasters increase. The mechanism of disaster risk is as follows. Agents only know that disasters may occur with a certain probability and on average are of a certain magnitude but their actual realization is uncertain. This source of uncertainty, coupled with agents' risk aversion, leads to engage in precautionary savings which decreases consumption and investment. It follows that the natural rate and inflation settle at lower levels than in a model without disasters. ${ }^{31}$

The impact of disasters on the risky steady state of inflation and the natural rate clearly depends on the distribution of those shocks, e.g. average size, variance and annual probability. Intuitively, the larger the expected impact and/or the probability of natural disasters, the lower are the natural rate and inflation at the risky steady state. To generalize these results, Figure 2 plots the natural rate and inflation for different size of disasters (left plot) and probability (right plot), under the standard Taylor rule. In particular, the average disaster size varies from $0 \%$ of GDP to $17.4 \%$ of GDP, which is the range of disaster impact in the data, while keeping the annual probability of the event fixed at $2.2 \% .^{32}$ The annual probability of experiencing a disaster varies from $0 \%$ (no disasters) to $10 \%$, which would imply, on average, one disaster in 10 years, while keeping the average size of the events fixed at $2.95 \%$ of GDP. For inflation (blue-solid lines) and the natural rate (red-dashed lines), Figure 2 also reports the values at the baseline calibration (vertical black-solid lines) and the inflation target (horizontal black-dashed lines). The natural rate and inflation stabilize

\footnotetext{
${ }^{30}$ See e.g. IPCC $(2014 ; 2018)$, Alfieri et al. (2015) and IMF, (2017) for projections on the frequency of natural disasters.

${ }^{31}$ Appendix E.1 discusses sensitivity analysis on various parameters, including those related to preferences and the disaster risk process (3).

${ }^{32}$ Assuming no damages from disasters is equivalent to a no disaster scenario. Indeed, results are equal to a distribution in which the annual probability of disasters is zero.
} 
Figure 2: Risky steady state of natural rate and inflation for different average disaster size and annual probability.
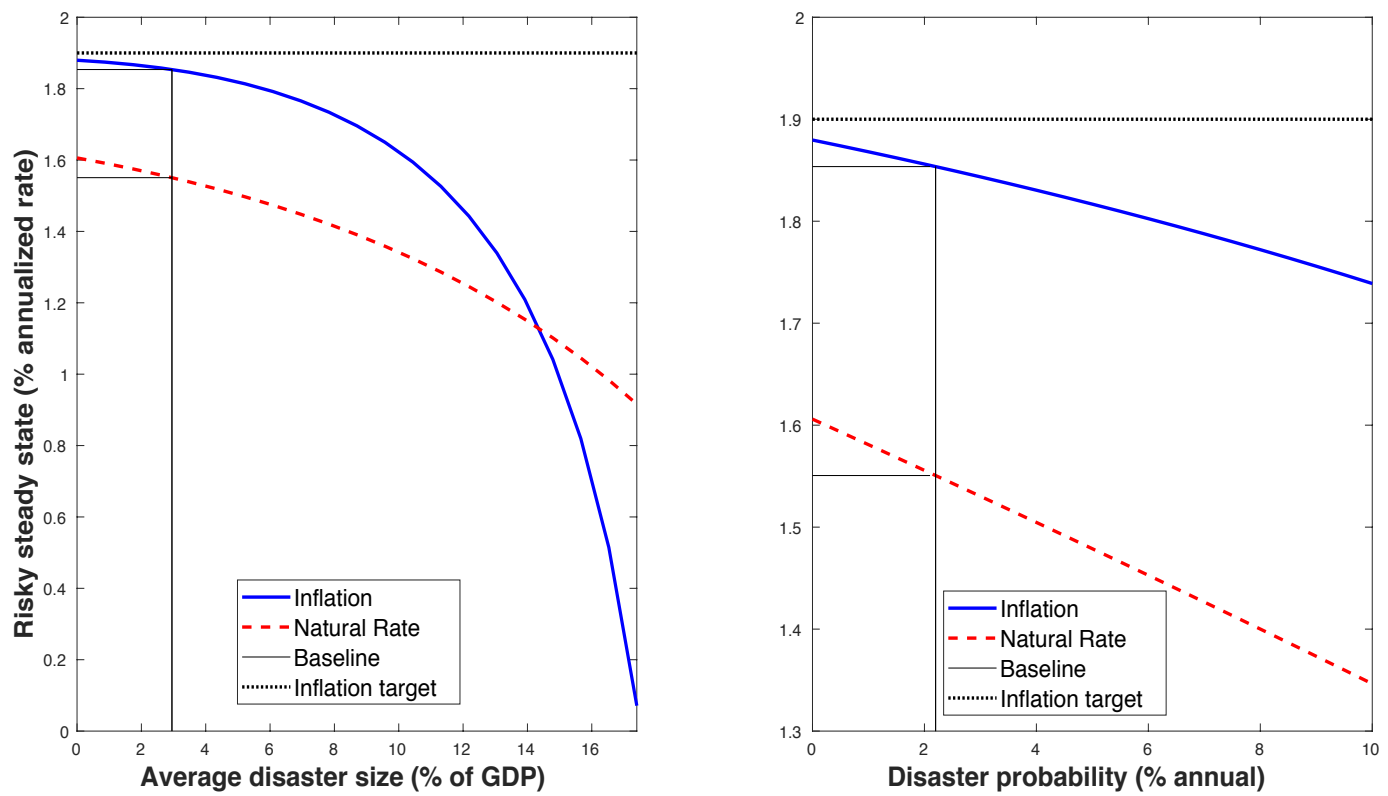

Notes: Risky steady state of the natural rate and inflation under the standard Taylor rule for different average disaster size (with fixed annual probability at $2.2 \%$, left plot) and annual probability (with fixed average damages at $2.95 \%$ of GDP, right plot). The risky steady state is calculated by simulating the model for 100 periods without shocks. Inflation and interest rates are in \% annualized values. The central bank's inflation target is $1.9 \%$.

at lower values as the average size and probability increase, suggesting that more frequent and powerful natural disasters, ex-ante, induce stronger precautionary savings. Results show that more frequent and/or more powerful natural disasters lead to stronger ex-ante effects whereby the natural rate and inflation fall to almost zero and these effects are nonlinear, especially as regards the average disaster size. The source of nonlinearities lies in the specification of preferences (e.g. risk aversion and the intertemporal elasticity of substitution). ${ }^{33}$ Figure 3 reports the risky steady states of the natural rate and inflation under different size of disasters and for three different calibrations of risk aversion (left plot) or of the inverse of the intertemporal elasticity of substitution (IES, right plot). In general, it can be observed that while risk aversion has a strong nonlinear effect on the natural rate and inflation, the IES mainly affects the deterministic steady state of the model, e.g. the point in which the average disaster size is zero. The left plot of Figure 3 reports the risky steady states for the baseline risk aversion $(\gamma=7$, solid lines $)$, for a halved risk aversion $(\gamma=3.5$, dashed

\footnotetext{
${ }^{33}$ It does not arise from occasionally binding constraints, e.g. borrowing constraints or the zero-lowerbound. While these represent interesting mechanisms, they would require a different solution method. We leave their assessment for future research.
} 
Figure 3: Risky steady state of natural rate and inflation for different preference parametersm and average disaster size.
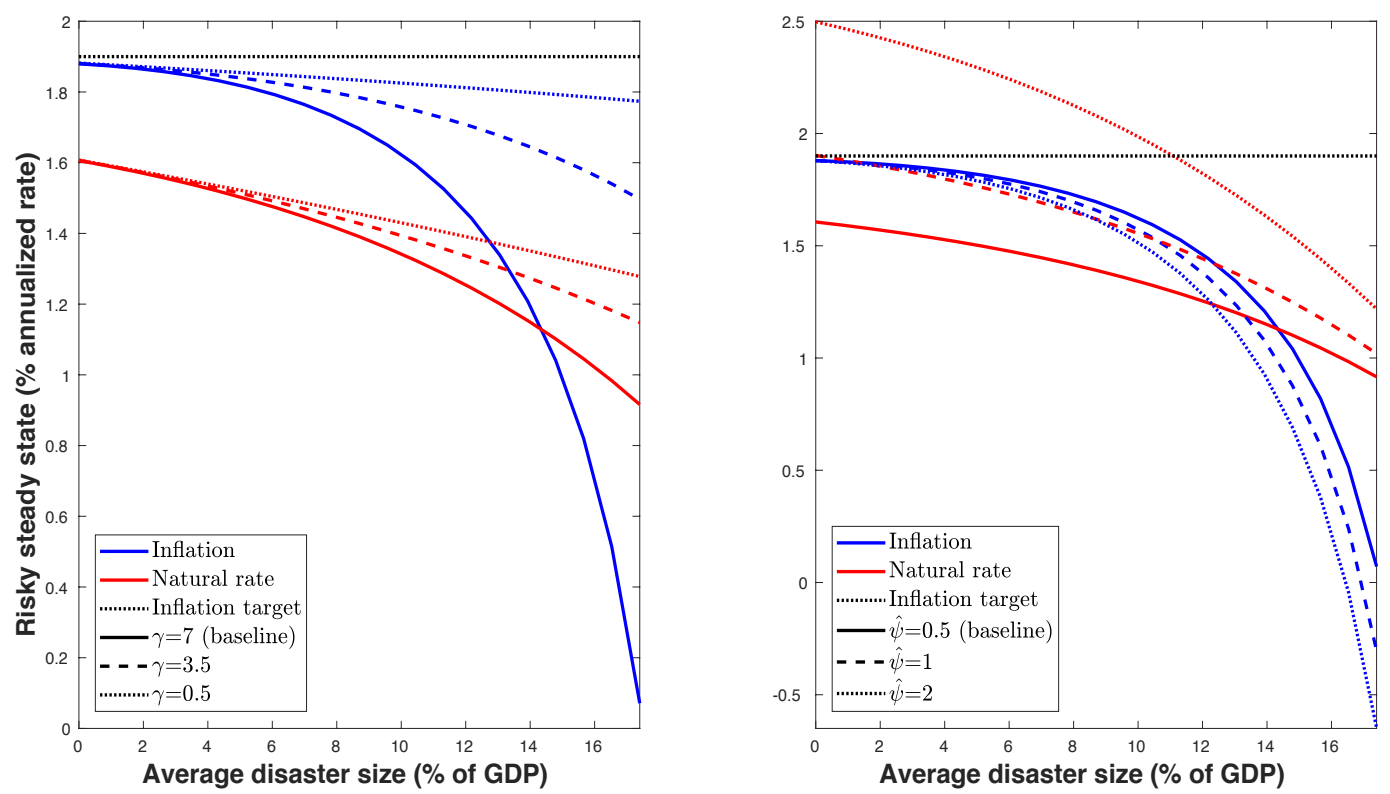

Notes: Risky steady state of the natural rate and inflation under the standard Taylor rule for different average disaster size (with fixed annual probability at $2.2 \%$ ), for three values of risk aversion (left plot) and inverse of the intertemporal elasticity of substitution (right plot). The risky steady state is calculated by simulating the model for 100 periods without shocks. Inflation and interest rates are in $\%$ annualized values. The central bank's inflation target is $1.9 \%$.

lines), and for a very low risk aversion ( $\gamma=0.5$, dotted lines). The latter case is particularly interesting since utility collapses to the standard expected utility with risk aversion equal to the inverse of the IES. ${ }^{34}$ Clearly, larger risk aversion makes the model more nonlinear in the average size of disasters. This highlights the importance of using Epstein-Zin preferences in such a context, that would otherwise miss much of the nonlinear effects of natural disasters. Indeed, when risk aversion is lowered to equal the inverse of the IES, much of the nonlinearities disappear. Conversely, the inverse of the IES mainly affects the level of the natural rate. Indeed, the right plot of Figure 3 reports the risky steady states for the baseline inverse IES ( $\hat{\psi}=0.5$, solid lines), for a twofold value ( $\hat{\psi}=1$, dashed lines), and for a larger value adopted by Isoré and Szczerbowicz (2017) ( $\hat{\psi}=2$, dotted lines). Higher inverse IES requires a higher natural rate in order for households to save. At the same time, a higher inverse IES lowers inflation which turns negative for large events.

To sum up, natural disasters risk might generate strong precautionary savings that cause

\footnotetext{
${ }^{34}$ These values of $\gamma$ are close to those employed in the literature on rare disasters (see e.g Barro, 2006; Gourio, 2012; Isoré and Szczerbowicz, 2017; Fernández-Villaverde and Levintal, 2018) while delivering a level of the natural interest rate at the risky steady state close to available estimates, as discussed in Section 4.
} 
the natural rate and inflation to stabilize at lower levels relative to an economy without disaster risk. The effects are particularly large and nonlinear if extreme events become more frequent, such that the natural rate might fall below $1 \%$ and inflation might substantially fall below target.

\section{$5.2 \quad E x$-post: disaster realization}

\subsubsection{Supply-side effects}

We now turn to study the dynamic implications of natural disasters under the three alternative monetary policy regimes. Figure 4 reports the impulse responses to an average disaster realization when the central bank alternatively follows a standard Taylor rule (bluesolid lines), a disaster-adjusted Taylor rule (red-dotted lines) and a strict inflation targeting (black-dashed lines). Since natural disasters are assumed to affect the growth rate of the real variables, capital, output, consumption and investment are in non-stationary form. Regardless of the monetary policy regime, a disaster destroys the capital stock and causes a loss in aggregate productivity. ${ }^{35}$ Since both the transitory and permanent components of productivity are affected, there is a partial recovery in aggregate productivity, output and consumption, that temporarily grow at a faster rate relative to their pre-disaster growth rate. ${ }^{36}$ However, there is a permanent effect meaning that the level of real variables and aggregate productivity is permanently lower than the level they would have reached without the disaster. Given the capital destruction, the marginal product of capital falls and investment becomes more profitable, households save less and invest more thus leading to a temporary increase in the natural interest rate. ${ }^{37}$ Moreover, capital destruction also leads to lower supply thus generating a temporary increase in inflation.

While the dynamics are pretty similar across the three regimes in the aftermath of disasters, some differences are worth discussing. A disaster-adjusted Taylor rule halves the initial output loss at the cost of temporarily higher inflation. Relative to the standard Taylor rule, the policy rate is lower than the pre-disaster level for about 6 quarters which allows private investment to drive the recovery. Conversely, inflation targeting calls for an immediate increase of the policy rate despite the drop in output in order to mitigate the inflationary

\footnotetext{
${ }^{35}$ The main transmission channel is found to be through the effect on productivity relative to the capital destruction.

${ }^{36}$ This result hinges on the calibration of $\omega$, the parameter governing the relative impact of disasters on the components of productivity. In this case, the persistence of the effects of natural disasters are driven by parameter $\rho_{a}$. For both parameters sensitivity analysis is conducted in Section E of the Appendix.

${ }^{37}$ Jorda et al. (2020) estimate that wars, being essentially negative supply shocks, make the natural rate increases in response to them. They posit that the effect of natural disasters are similar to wars hence they expect the natural rate to increase.
} 
Figure 4: Impulse responses to an average disaster shock under alternative monetary policy regimes.
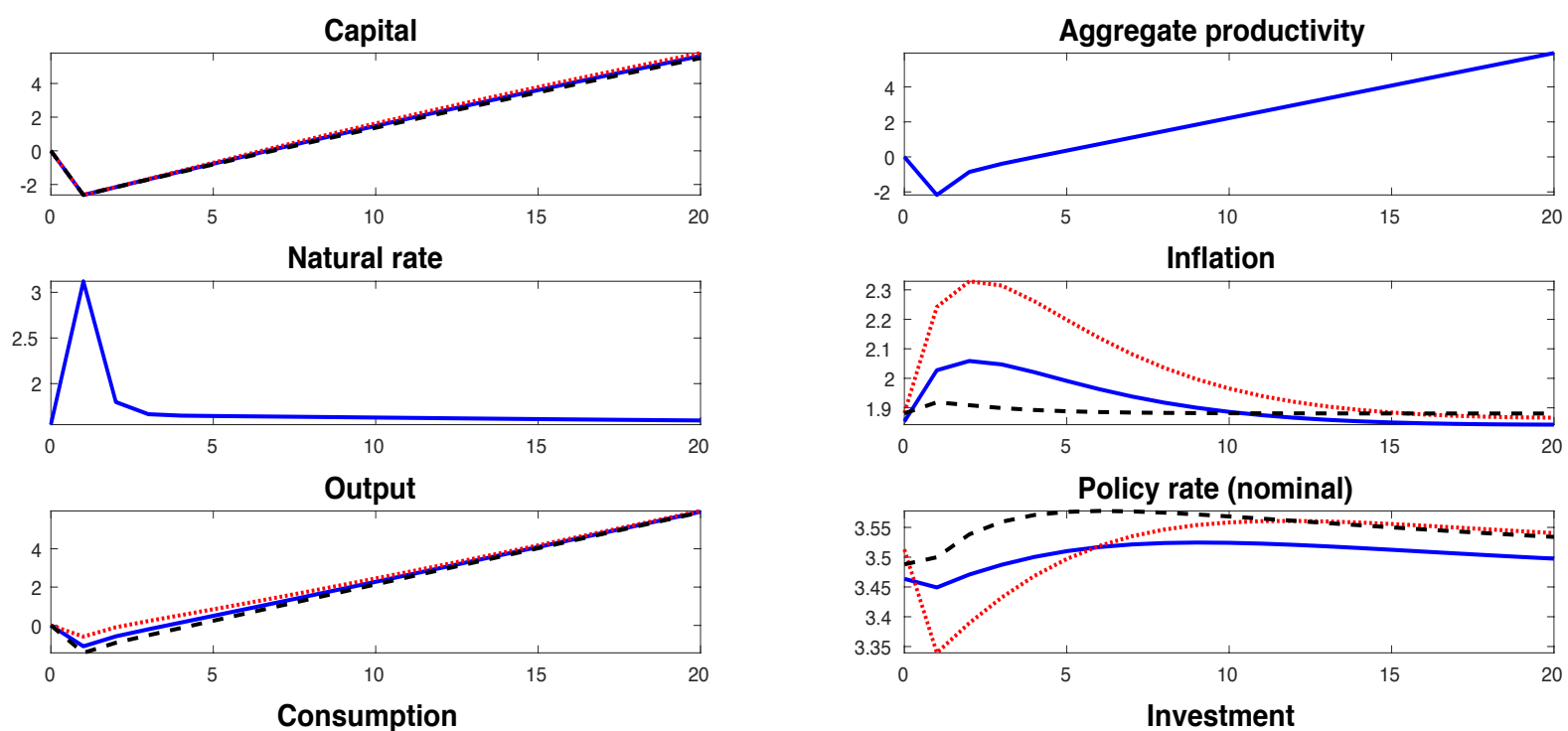

Policy rate (nominal)
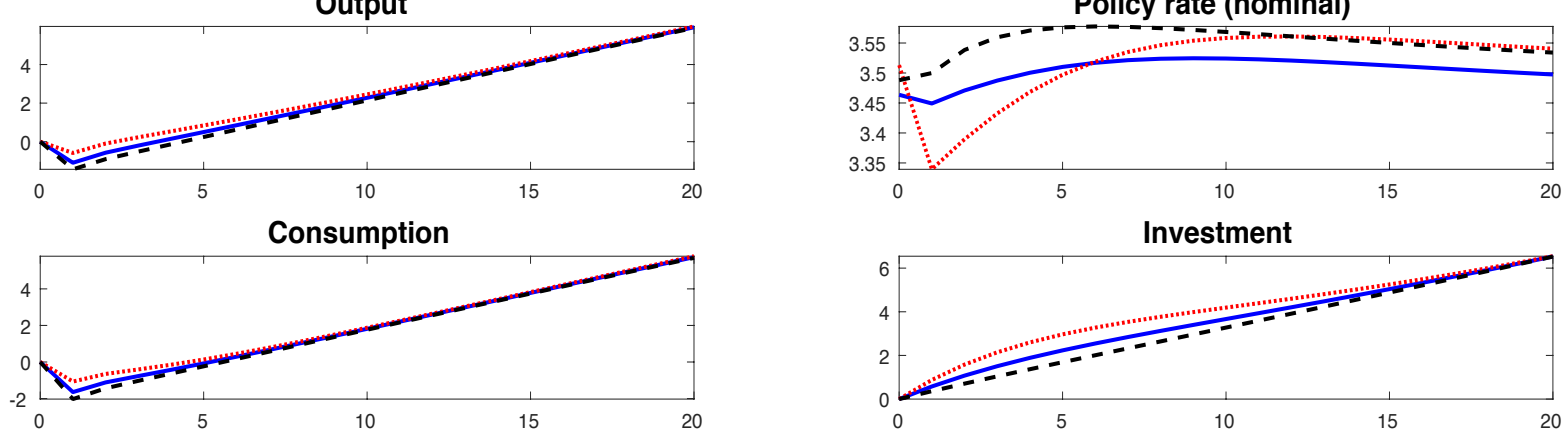

Standard Taylor Rule .......... Disaster-Taylor Rule - - - Inflation Targeting

Notes: Impulse responses to an average disaster shock equal to $2.95 \%$ of GDP. Output, consumption, investment, capital and productivity are expressed in non-stationary form and in percent deviations from the risk steady state. The risky steady state is calculated by simulating the model for 100 periods without shocks. Inflation and interest rates are in percent annualized terms.

pressures. This is consistent with the empirical evidence in Fratzscher et al. (2020), who estimate that in inflation targeting countries inflation rises only modestly, contrary to what happens under alternative regimes (they estimate an increase of annualized inflation of 0.56 percentage point in inflation targeting countries against 3.2 percentage points in non inflation targeters).

\subsubsection{Demand-side effects}

The model presented in Section 3 allows only for the supply-side effects of disaster realizations via capital destruction and TFP loss. However, empirical evidence is rather limited and not conclusive. While some papers support the view that natural disasters (as well as wars) are negative supply shocks, with capital destruction and higher natural rate and inflation (see e.g. Heinen et al., 2018; Fratzscher et al., 2020 and Jorda et al., 2020), they may entail larger demand-side effects with inflation falling and central banks responding by implementing 
expansionary policies. ${ }^{38}$ It is therefore interesting to explore what would happen should demand-side effects prevail on the supply-side effects a disaster realization. In order to do so while keeping the model parsimonious, we assume that agents are temporarily more risk averse in the aftermath of disasters. ${ }^{39}$ While some empirical evidence (mainly based on experiments) for developing and emerging market economies supports this assumption (see e.g. van den Berg et al. 2009; Cameron and Shah 2015; Cassar et al. 2017) it is not hard to imagine that also in OECD countries risk attitudes might change in the aftermath of natural disasters. Without referring to natural disasters, Kozlowski et al. (2020) show that one a rare event occurs, it permanently enters agents' information set and the tail of the shock distribution becomes larger, e.g. they attach a larger probability to the tail event because they believe it will materialize again. Such belief revisions ultimately induces precautionary savings and keeps output and interest rates low. Without modifying beliefs in our model, we can capture a similar effect by making risk aversion $\gamma$ time-varying and depending on disasters:

$$
\gamma_{t}=\gamma e^{\zeta \log \left(\frac{\tau_{t}}{\tau}\right)}
$$

where $\zeta$ governs the responsiveness of risk aversion to the exogenous variable $\tau_{t}$, whose logarithm follows a $\mathrm{AR}(1)$ process:

$$
\log \left(\frac{\tau_{t}}{\tau}\right)=\rho_{\tau}\left(\frac{\tau_{t-1}}{\tau}\right)+d_{t} \theta_{t}
$$

According to (29) and (30), when a disaster realizes agents become temporarily more risk averse, with $\rho_{\tau} \in[0,1]$ governing the persistence of this effect. For a sufficiently high $\zeta$ and $\rho_{\tau}$, demand-side effects might prevail, with higher precautionary savings causing the natural rate and inflation to fall.

This scenario is depicted in Figure 5 where the blue lines report the impulse responses to an average natural disaster in the baseline model with only supply-side effects are at work, while the blue-solid lines describe the dynamics when the shock to risk aversion is activated. The central bank is assumed to follow a standard Taylor rule. As an illustration, we calibrate $\zeta=0.5$ and $\rho_{\tau}=0.85$. A high persistence of the shock to risk aversion is consistent with Kozlowski et al. (2020) since it captures the persistent effects of a disaster on households' behavior who increase their precautionary savings. However, there is uncertainty about how to calibrate them. Intuitively, lower values of $\zeta$ and $\rho_{\tau}$ would make the demand effects milder, possibly weaker than the supply-side effects. The values chosen to produce Figure

\footnotetext{
${ }^{38}$ See the anecdotal evidence on the responses of the FRBNZ and BOJ to the earthquakes that hit Christchurch and East Japan in 2011 discussed in Section 1.

${ }^{39}$ Alternatively, one could assume that natural disasters might generate financial distress and increase risk premia. Qualitatively, the effects are similar to those shown here and are discussed in Appendix F.
} 
Figure 5: Impulse responses to an average disaster shock with and without shock to risk aversion.
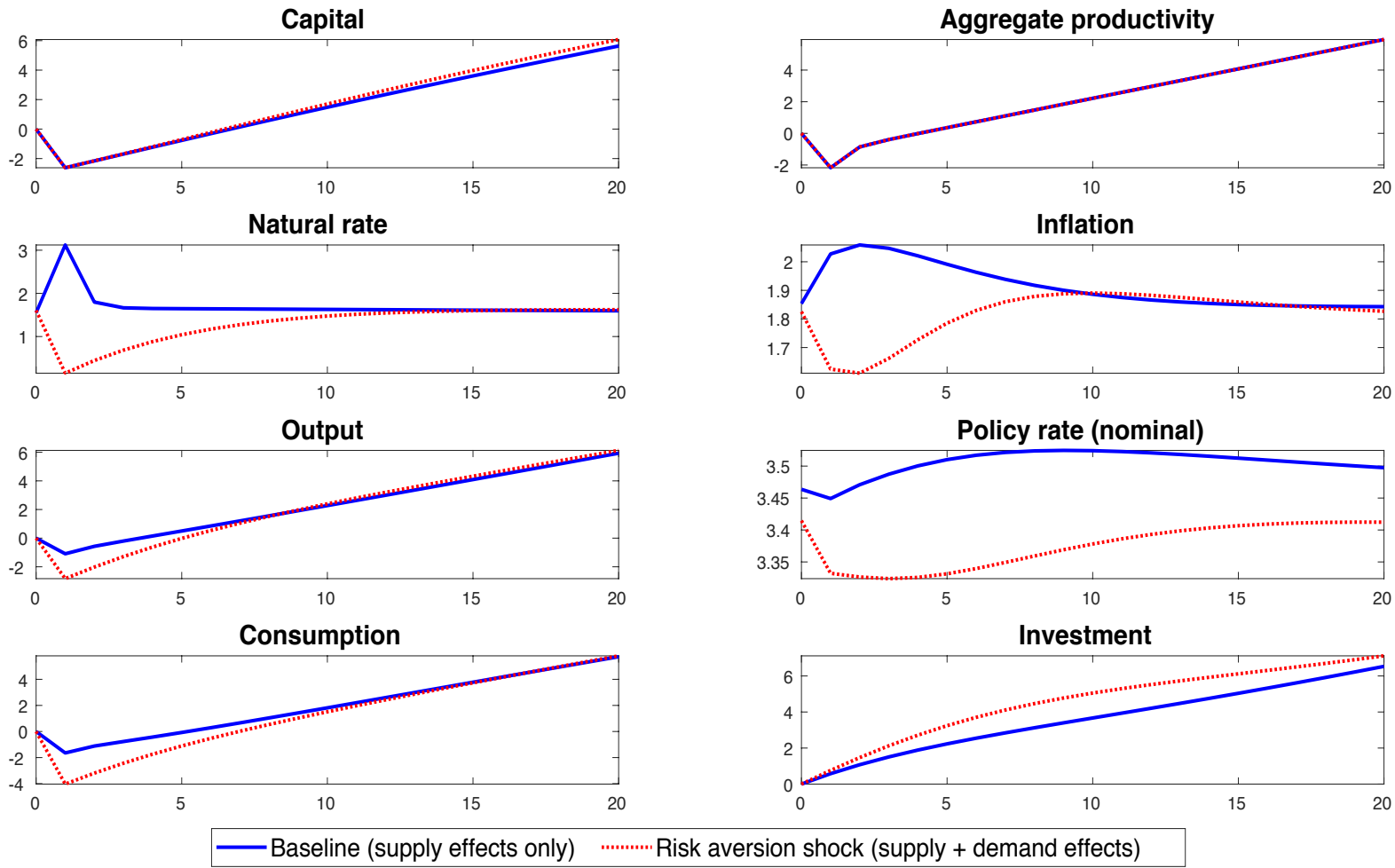

Notes: Impulse responses to an average disaster shock equal to $2.95 \%$ of GDP under the standard Taylor rule, when the shock to risk aversion is not activated (supply effects only, blue-solid lines), and when it is activated (supply + demand effects, red-dotted lines). Output, consumption, investment, capital and productivity are expressed in non-stationary form and in percent deviations from the risk steady state. The risky steady state is calculated by simulating the model for 100 periods without shocks. Inflation and interest rates are in percent annualized terms.

5 generate larger demand-side effects. In addition to temporarily lower natural rate and inflation, the main differences relative to the baseline model are in the policy response, which is persistently expansionary when demand-side effects dominate. Despite the policy response, the amplification induced by the shock to risk aversion more than doubles the output loss. While illustrative, this mechanism shows that if demand-side effects of natural disasters prevail, output losses might be larger. ${ }^{40}$ Finally, Figure 6 reports the impulse responses to an average disaster shock when the shock to risk aversion is activated under the three alternative monetary policy regimes under scrutiny. While a strict inflation targeting regime brings inflation at target faster, the disaster Taylor rule generates an overshoot in inflation because the policy rate, after an initial larger decrease, it is more gradually increased. Nevertheless,

\footnotetext{
${ }^{40}$ Ex-ante, the effects are very small. The natural rate is slightly higher because agents know that they will be more risk averse ex-post hence save less ex-ante.
} 
Figure 6: Impulse responses to an average disaster shock with shock to risk aversion under alternative monetary policy regimes.
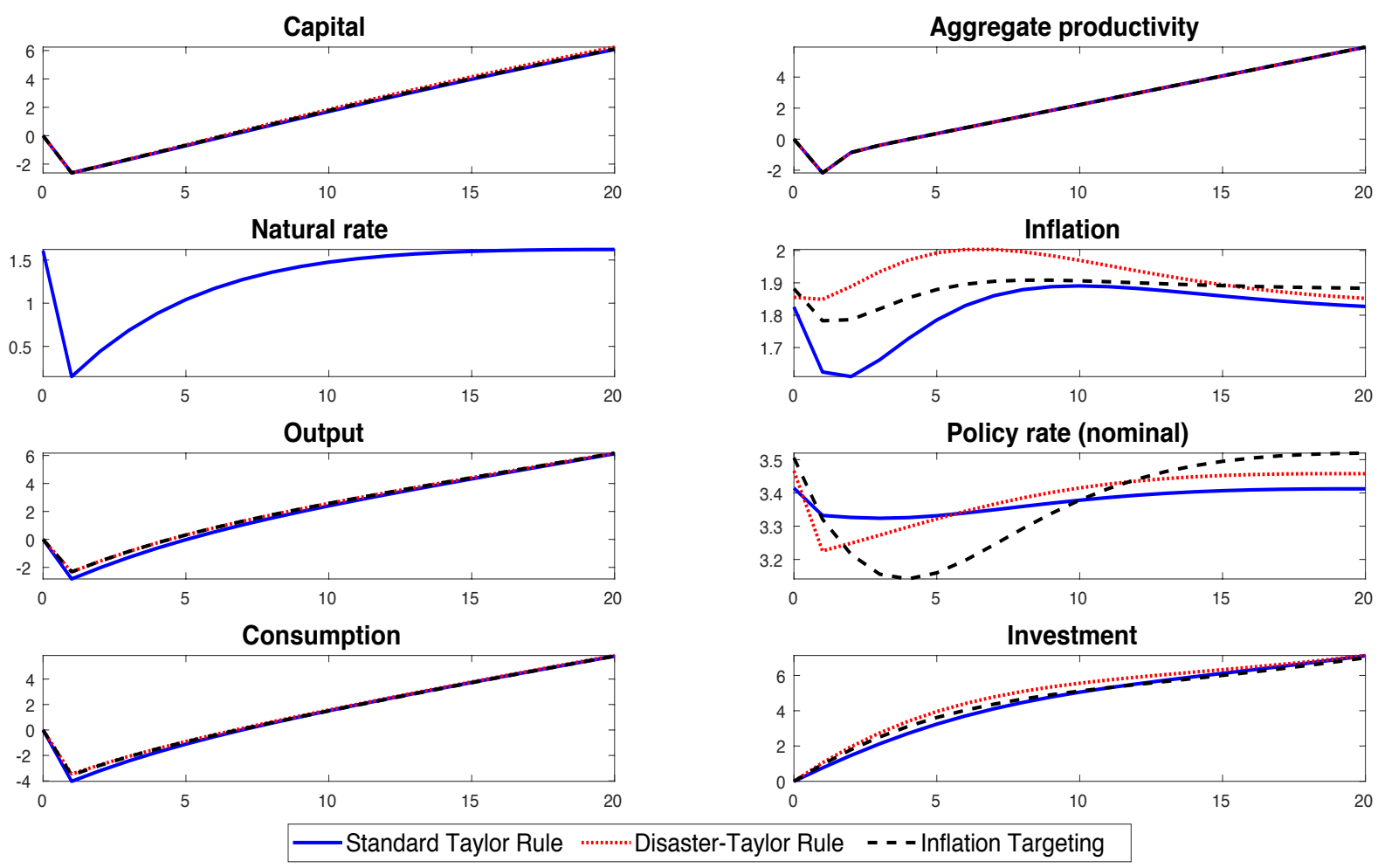

Notes: Impulse responses to an average disaster shock equal to $2.95 \%$ of GDP under the three alternative monetary policy regimes when the shock to risk aversion is activated. Output, consumption, investment, capital and productivity are expressed in non-stationary form and in percent deviations from the risk steady state. The risky steady state is calculated by simulating the model for 100 periods without shocks. Inflation and interest rates are in percent annualized terms.

despite the regime implemented, the central bank lowers the policy rate when demand-side effects of natural disasters prevail.

\section{Conclusions}

This paper contributes to the ongoing debate on the macroeconomic effects of natural disasters in OECD countries, by assessing the ex-ante and ex-post effects of natural disasters on the natural interest rate and inflation. Ex-ante, disaster risk exerts downward pressures on the natural rate and inflation. These effects are shown to become particularly sizable and nonlinear if extreme natural disasters become more frequent, as suggested by climate change scenarios, potentially bringing the natural rate to a very low level and inflation far below target. Ex-post, a disaster realization might lead to temporarily higher or lower natural 
rate and inflation, depending on whether supply- or demand-side effects dominate. From a central bank's perspective, these require different policy responses in order to keep inflation close to target and/or mitigate output losses.

The paper hence shows the relevance of incorporating climate change risk and the occurrence of natural disasters in the central bank's assessment of the natural rate and inflation. A welfare analysis of the effects of natural disasters and optimal monetary policy responses, as well as of the relevance of occasionally binding constraints, are left for future research. Finally, the methodology employed lends itself to the study of other types of rare events, such as the Covid-19 pandemic and its implications for the conduct of monetary policy.

\section{References}

Alfieri, L., Burek, P., Feyen, L., and Forzieri, G. (2015). Global warming increases the frequency of river floods in europe. Hydrology and Earth System Sciences, 19(5):22472260 .

Andreasen, M. (2012). On the Effects of Rare Disasters and Uncertainty Shocks for Risk Premia in Non-Linear DSGE Models. Review of Economic Dynamics, 15(3):295-316.

Barro, R. J. (2006). Rare Disasters and Asset Markets in the Twentieth Century. The Quarterly Journal of Economics, 121(3):823-866.

Barro, R. J. and Ursua, J. F. (2008). Macroeconomic Crises since 1870. Brookings Papers on Economic Activity, 39(1 (Spring):255-350.

Barro, R. J. and Ursua, J. F. (2012). Rare Macroeconomic Disasters. Annual Review of Economics, 4(1):83-109.

Barsky, R., Justiniano, A., and Melosi, L. (2014). The natural rate of interest and its usefulness for monetary policy. American Economic Review, 104(5):37-43.

Burke, M., Solomon M., H., and Miguel, E. (2015). Global non-linear effect of temperature on economic production. Nature, 527(15725).

Caldara, D., Fernandez, J., Rubio-Ramirez, J., and Yao, W. (2012). Computing DSGE models with recursive preferences and stochastic volatility. Review of Economic Dynamics, $15(2): 188-206$.

Cameron, L. and Shah, M. (2015). Risk-taking behavior in the wake of natural disasters. Journal of Human Resources, 50(2):484-515.

Cantelmo, A., Melina, G., and Papageorgiou, C. (2019). Macroeconomic Outcomes in Disaster-Prone Countries. IMF Working Papers 19/217, International Monetary Fund.

Cassar, A., Healy, A., and von Kessler, C. (2017). Trust, risk, and time preferences after a natural disaster: experimental evidence from Thailand. World Development, 94(C):90105.

Christiano, L. J., Eichenbaum, M., and Evans, C. L. (2005). Nominal rigidities and the dynamic effects of a shock to monetary policy. Journal of Political Economy, 113(1):1-45.

Coenen, G., Karadi, P., Schmidt, S., and Warne, A. (2018). The New Area-Wide Model II: 
an extended version of the ECB?s micro-founded model for forecasting and policy analysis with a financial sector. Working Paper Series 2200, European Central Bank.

Coeurdacier, N., Rey, H., and Winant, P. (2011). The Risky Steady State. American Economic Review, 101(3):398-401.

Cúrdia, V., Del Negro, M., and Greenwald, D. L. (2014). Rare shocks, great recessions. Journal of Applied Econometrics, 29(7):1031-1052.

Del Negro, M., Giannone, D., Giannoni, M. P., and Tambalotti, A. (2017). Safety, Liquidity, and the Natural Rate of Interest. Brookings Papers on Economic Activity, 48(1 (Spring):235-316.

Epstein, L. G. and Zin, S. E. (1989). Substitution, risk aversion, and the temporal behavior of consumption and asset returns: A theoretical framework. Econometrica, 57(4):937-969.

Fernández-Villaverde, J. and Levintal, O. (2018). Solution methods for models with rare disasters. Quantitative Economics, 9(2):903-944.

Fisher, J. D. (2015). On the structural interpretation of the smets?wouters ?risk premium? shock. Journal of Money, Credit and Banking, 47(2-3):511-516.

Fomby, T., Ikeda, Y., and Loayza, N. V. (2013). The growth aftermath of natural disasters. Journal of Applied Econometrics, 28(3):412-434.

Fratzscher, M., Grosse-Steffen, C., and Rieth, M. (2020). Inflation targeting as a shock absorber. Journal of International Economics, page 103308.

Gabaix, X. (2011). Disasterization: A Simple Way to Fix the Asset Pricing Properties of Macroeconomic Models. American Economic Review, 101(3):406-409.

Gabaix, X. (2012). Variable Rare Disasters: An Exactly Solved Framework for Ten Puzzles in Macro-Finance. The Quarterly Journal of Economics, 127(2):645-700.

Gourio, F. (2012). Disaster risk and business cycles. American Economic Review, 102(6):2734-66.

Gourio, F., Kashyap, A. K., and Sim, J. W. (2018). The Trade offs in Leaning Against the Wind. IMF Economic Review, 66(1):70-115.

Gourio, F., Siemer, M., and Verdelhan, A. (2013). International risk cycles. Journal of International Economics, 89(2):471-484.

Guerrieri, V., Lorenzoni, G., Straub, L., and Werning, I. (2020). Macroeconomic Implications of COVID-19: Can Negative Supply Shocks Cause Demand Shortages? NBER Working Papers 26918, National Bureau of Economic Research, Inc.

Heinen, A., Khadan, J., and Strobl, E. (2018). The price impact of extreme weather in developing countries. The Economic Journal, 0(0).

Hills, T. S., Nakata, T., and Schmidt, S. (2019). Effective lower bound risk. European Economic Review, 120:103321.

Holston, K., Laubach, T., and Williams, J. C. (2017). Measuring the natural rate of interest: International trends and determinants. Journal of International Economics, 108:S59 - S75. 39th Annual NBER International Seminar on Macroeconomics.

Hsiang, S. M. and Jina, A. S. (2014). The Causal Effect of Environmental Catastrophe on Long-Run Economic Growth: Evidence From 6,700 Cyclones. NBER Working Papers 20352, National Bureau of Economic Research, Inc.

Intergovernmental Panel on Climate Change (2014). Climate Change 2014: Impacts, Adaptation, and Vulnerability. Part A: Global and Sectoral Aspects. Contribution of working group ii to the fifth assessment report of the intergovernmental panel on climate change. 
Intergovernmental Panel on Climate Change (2018). Special Report: Global Warming of 1.5 ${ }^{\circ} \mathrm{C}$. Technical report.

International Monetary Fund (2017). The effects of weather shocks on economic activity: how can low income countries cope? World economic outlook, International Monetary Fund.

Isoré, M. and Szczerbowicz, U. (2017). Disaster risk and preference shifts in a New Keynesian model. Journal of Economic Dynamics and Control, 79(C):97-125.

Isoré, M. (2018). Changes in Natural Disaster Risk: Macroeconomic Responses in Selected Latin American Countries. Economies, 6(1):1-12.

Jorda, O., Sing, S. R., and Taylor, A. M. (2020). Longer-run Economic Consequences of Pandemics. NBER Working Papers 26934, National Bureau of Economic Research, Inc.

Keen, B. D. and Pakko, M. R. (2011). Monetary policy and natural disasters in a dsge model. Southern Economic Journal, 77(4).

Kim, J. and Ruge-Murcia, F. (2019). Extreme events and optimal monetary policy. International Economic Review, 60(2):939-963.

Klomp, J. (2020). Do natural disasters affect monetary policy? a quasi-experiment of earthquakes. Journal of Macroeconomics, 64:103164.

Kozlowski, J., Veldkamp, L., and Venkateswaran, V. (2018). The Tail that Keeps the Riskless Rate Low. NBER Working Papers 24362, National Bureau of Economic Research, Inc.

Kozlowski, J., Veldkamp, L., and Venkateswaran, V. (2020). The tail that wags the economy: Beliefs and persistent stagnation. Journal of Political Economy, 128(8):2839-2879.

Lettau, M. (2003). Inspecting the mechanism: Closed-form solutions for asset prices in real business cycle models. The Economic Journal, 113(489):550-575.

Levintal, O. (2018). Taylor projection: A new solution method for dynamic general equilibrium models. International Economic Review, 59(3):1345-1373.

Lucas, Robert E, J. (1978). Asset Prices in an Exchange Economy. Econometrica, 46(6):14291445.

Mackowiak, B. and Wiederholt, M. (2018). Lack of preparation for rare events. Journal of Monetary Economics, 100(C):35-47.

Nakamura, E., Steinsson, J., Barro, R., and Ursúa, J. (2013). Crises and recoveries in an empirical model of consumption disasters. American Economic Journal: Macroeconomics, $5(3): 35-74$.

Neri, S. and Gerali, A. (2017). Natural rates across the Atlantic. Temi di discussione (Economic working papers) 1140, Bank of Italy, Economic Research and International Relations Area.

Nordhaus, W. (2019). Climate change: the ultimate challenge for economics. American Economic Review, 109(6):1991-2014.

Parker, M. (2018). The Impact of Disasters on Inflation. Economics of Disasters and Climate Change, 2(1):21-48.

Smets, F. and Wouters, R. (2003). An estimated dynamic stochastic general equilibrium model of the euro area. Journal of the European Economic Association, 1(5):1123-1175.

Smets, F. and Wouters, R. (2005). Comparing shocks and frictions in us and euro area business cycles: a bayesian dsge approach. Journal of Applied Econometrics, 20(2):161183.

Smets, F. and Wouters, R. (2007). Shocks and Frictions in US Business Cycles: A Bayesian 
DSGE Approach. American Economic Review, 97(3):586-606.

Summers, L. (2014). U.s. economic prospects: Secular stagnation, hysteresis, and the zero lower bound. Business Economics, 49(2):65-73.

van Binsbergen, J. H., Fernández-Villaverde, J., Koijen, R. S., and Rubio-RamÃrez, J. (2012). The term structure of interest rates in a DSGE model with recursive preferences. Journal of Monetary Economics, 59(7):634-648.

van den Berg, M., Fort, R., and Burger, K. (2009). Natural hazards and risk aversion: experimental evidence from Latin America. Technical report.

Villa, S. (2016). Financial Frictions In The Euro Area And The United States: A Bayesian Assessment. Macroeconomic Dynamics, 20(05):1313-1340.

Wieland, J. F. (2019). Are negative supply shocks expansionary at the zero lower bound? Journal of Political Economy, 127(3):973-1007. 


\section{Appendix}

\section{A Evidence on natural disasters}

Table 4: Natural disasters in OECD countries (1960-2018).

\begin{tabular}{|c|c|c|c|c|}
\hline Country & Year & Type(s) & Climate-related & Damages ( $\%$ of GDP) \\
\hline Chile & 2010 & Earthquake & No & 17.40 \\
\hline New Zealand & 2011 & Earthquake & No & 12.30 \\
\hline Chile & 1985 & Earthquake & No & 7.64 \\
\hline Turkey & 1999 & Earthquake & No & 7.62 \\
\hline New Zealand & 2010 & Earthquake & No & 5.36 \\
\hline Italy & 1980 & Earthquake & No & 5.08 \\
\hline Chile & 1963 & Earthquake & No & 4.34 \\
\hline Australia & 1981 & Storm & Yes & 4.14 \\
\hline Japan & 2011 & Earthquake & No & 3.68 \\
\hline Czech Republic & 2002 & Storm, Flood & Yes & 3.58 \\
\hline Luxembourg & 1990 & $\begin{array}{l}\text { Storm } \\
\text { Storm }\end{array}$ & Yes & $\begin{array}{l}3.00 \\
3.56\end{array}$ \\
\hline Italy & 1966 & Flood & Yes & 2.94 \\
\hline Iceland & 1973 & Volcanic activity & No & 2.94 \\
\hline Greece & 1999 & Earthquake & No & 2.91 \\
\hline Czech Republic & 1997 & Flood & Yes & 2.76 \\
\hline Chile & 1971 & Earthquake & No & 2.62 \\
\hline Australia & 1967 & Wildfire & Yes & 2.45 \\
\hline Latvia & 2005 & Storm & Yes & 2.26 \\
\hline Chile & 1965 & Earthquake, Flood & No & 2.26 \\
\hline Mexico & 1985 & Earthquake & No & 2.23 \\
\hline New Zealand & 2016 & Earthquake, Flood & No & 2.21 \\
\hline Poland & 1997 & Flood & Yes & 2.19 \\
\hline Japan & 1995 & Earthquake, Flood, Storm & No & 2.04 \\
\hline Spain & 1983 & Flood & Yes & 1.99 \\
\hline Australia & 1974 & Flood, Storm & Yes & 1.73 \\
\hline Greece & 1981 & Earthquake & No & 1.58 \\
\hline $\begin{array}{l}\text { Italy } \\
\text { Itale }\end{array}$ & $\begin{array}{l}1901 \\
1976\end{array}$ & Earthquake & No & 1.58 \\
\hline Greece & 1986 & Earthquake & No & 1.56 \\
\hline Denmark & 1999 & Storm & Yes & 1.47 \\
\hline Canada & 1977 & Drought & Yes & 1.45 \\
\hline USA & 2005 & Storm, Wildfire & Yes & 1.30 \\
\hline Portugal & 2003 & Wildfire & Yes & 1.29 \\
\hline Greece & 1990 & Drought & Yes & 1.26 \\
\hline Austria & 2002 & Storm & Yes & 1.22 \\
\hline Japan & 1964 & Earthquake & No & 1.15 \\
\hline Chile & 2015 & Flood, Earthquake, Volcanic Activity & No & 1.11 \\
\hline Hungary & 1992 & Drought & Yes & 1.10 \\
\hline Australia & 2010 & Flood, Storm & Yes & 1.09 \\
\hline Spain & 1990 & Drought & Yes & 1.08 \\
\hline Estonia & 2005 & Storm & Yes & 1.07 \\
\hline Republic of Korea & 1967 & Flood & Yes & 1.05 \\
\hline USA & 2017 & Wildfire & Yes & 1.02 \\
\hline Japan & 2004 & Earthquake, Flood, Storm & No & 1.01 \\
\hline Mexico & 2005 & Storm & Yes & 1.01 \\
\hline Slovenia & 2007 & Storm & Yes & 1.00 \\
\hline
\end{tabular}

Sources: EM-DAT and authors' calculations. Damages are expressed in percent of previous year's GDP.

Calculation of annual probability Following Barro (2006) and Barro and Ursua (2008; 2012), it is computed as follows:

1. The sample length is $t$ years.

2. The number of countries considered is 36 .

3. Pool the countries and obtain a sample length of $t \times 36=n$ years.

4. Sum the disaster years (peak-to-trough years of GDP) of all countries: $x$ years with disasters. 
5. Compute the number of normalcy (e.g. no disasters) years: $n-x$ years without disasters.

6. Compute the probability of experiencing a disaster in a normalcy year (number of disaster years over normalcy years): $p_{d}^{a n n}=\frac{x}{n-x}$.

\section{B The stationary model}

The model exhibits a stochastic trend growth rate hence we detrend it before finding the solution. In general, variables are detrended by $z_{t}=A_{t}^{\frac{1}{1-\alpha}}$ unless otherwise stated. We denote the detrended variable with a $\ll^{\sim} \gg$, i.e. $\tilde{x}_{t}=\frac{x_{t}}{z_{t}}$, while growth rates are denoted by a $\ll \gg$, i.e. $\hat{x}_{t}=\frac{x_{t}}{x_{t-1}}$. The full detrended system is the following:

$$
\begin{aligned}
d_{t+1} & =\mu^{d}+\left(\epsilon_{d, t+1}-\mu^{d}\right) \\
\log \theta_{t+1} & =\left(1-\rho_{\theta}\right) \log \bar{\theta}+\rho_{\theta} \log \theta_{t}+\sigma_{\theta} \epsilon_{\theta, t+1} \\
z_{A, t+1} & =\sigma_{A} \epsilon_{A, t+1} \\
m_{t+1} & =\sigma_{m} \epsilon_{m, t+1} \\
\xi_{t+1} & =\rho_{\xi} \xi_{t}+\sigma_{\xi} \epsilon_{\xi, t+1} \\
\log \hat{\mu}_{t+1} & =\sigma_{\mu} \epsilon_{\mu, t+1} \\
\log \hat{A}_{t} & =\Lambda_{A}+z_{A, t}-(1-\alpha) d_{t} \theta_{t} \\
\log \hat{z}_{t} & =\frac{1}{1-\alpha} \log \hat{A}_{t} \\
\tilde{V}_{t}^{1-\psi} & =\tilde{U}_{t}^{1-\psi}+\beta E_{t}\left(\tilde{V}_{t+1}^{1-\gamma} \hat{z}_{t+1}^{1-\gamma}\right)^{\frac{1-\psi}{1-\gamma}} \\
\tilde{U}_{t} & =\tilde{c}_{t}\left(1-l_{t}\right)^{\nu} e^{\xi_{t}} \\
\tilde{U}_{c, t} & =\left(1-l_{t}\right)^{\nu} e^{\xi_{t}} \\
\tilde{U}_{l, t} & =-\nu \tilde{c}_{t}\left(1-l_{t}\right)^{\nu-1} e^{\xi_{t}} \\
\tilde{\lambda}_{t} & =(1-\psi) \tilde{U}_{t}^{-\psi} \tilde{U}_{c, t} \\
-\tilde{\lambda}_{t} \tilde{w}_{t} & =(1-\psi) \tilde{U}_{t}^{-\psi} \tilde{U}_{l, t} \\
M_{t+1} & =\beta \frac{\tilde{\lambda}_{t+1}}{\tilde{\lambda}_{t}} \hat{z}_{t+1}^{-\psi} \frac{\left(\frac{\tilde{V}_{t+1}}{\tilde{V}^{s s}}\right)^{\psi-\gamma} \hat{z}_{t+1}^{\psi-\gamma}}{E_{t}\left(\left(\frac{\tilde{V}_{t+1}}{\tilde{V}^{s s}}\right)^{1-\gamma} \hat{z}_{t+1}^{1-\gamma}\right)^{\frac{\psi-\gamma}{1-\gamma}}} \\
1 & =E_{t} M_{t+1} \frac{R_{t}}{\Pi_{t+1}}
\end{aligned}
$$




$$
\begin{aligned}
& \tilde{q}_{t}=E_{t} M_{t+1} \exp \left(-d_{t+1} \theta_{t+1}\right) \frac{\left[\tilde{r}_{t+1}+\tilde{q}_{t+1}(1-\delta)\right]}{\hat{\mu}_{t+1}} \\
& 1=\tilde{q}_{t}\left[1-S\left[\frac{\tilde{x}_{t}}{\tilde{x}_{t-1}} \hat{z}_{t}\right]-S^{\prime}\left[\frac{\tilde{x}_{t}}{\tilde{x}_{t-1}} \hat{z}_{t}\right] \frac{\tilde{x}_{t}}{\tilde{x}_{t-1}} \hat{z}_{t}\right]+ \\
& +E_{t} M_{t+1} \tilde{q}_{t+1} S^{\prime}\left[\frac{\tilde{x}_{t+1}}{\tilde{x}_{t}} \hat{z}_{t+1}\right]\left(\frac{\tilde{x}_{t+1}}{\tilde{x}_{t}} \hat{z}_{t+1}\right)^{2} \\
& S\left[\frac{\tilde{x}_{t}}{\tilde{x}_{t-1}} \hat{z}_{t}\right]=\frac{\kappa}{2}\left(\frac{\tilde{x}_{t}}{\tilde{x}_{t-1}} \hat{z}_{t}-\hat{z}\right)^{2} \\
& S^{\prime}\left[\frac{\tilde{x}_{t}}{\tilde{x}_{t-1}} \hat{z}_{t}\right]=\kappa\left(\frac{\tilde{x}_{t}}{\tilde{x}_{t-1}} \hat{z}_{t}-\hat{z}\right) \\
& \tilde{k}_{t}^{*}=(1-\delta) \tilde{k}_{t}+\left(1-S\left[\frac{\tilde{x}_{t}}{\tilde{x}_{t-1}} \hat{z}_{t}\right]\right) \tilde{x}_{t} \\
& \tilde{k}_{t}=\frac{\tilde{k}_{t-1}^{*}}{\hat{z}_{t}} \exp \left(-d_{t} \theta_{t}\right) \\
& \tilde{g}_{t}^{1}=m c_{t} \tilde{y}_{t}+\theta_{p} E_{t} M_{t+1}\left(\frac{\Pi_{t}^{\chi}}{\Pi_{t+1}}\right)^{-\epsilon} \tilde{g}_{t+1}^{1} \hat{z}_{t+1} \\
& \tilde{g}_{t}^{2}=\Pi_{t}^{*} \tilde{y}_{t}+\theta_{p} E_{t} M_{t+1}\left(\frac{\Pi_{t}^{\chi}}{\Pi_{t+1}}\right)^{1-\epsilon}\left(\frac{\Pi_{t}^{*}}{\Pi_{t+1}^{*}}\right) \tilde{g}_{t+1}^{2} \hat{z}_{t+1} \\
& \epsilon \tilde{g}_{t}^{1}=(\epsilon-1) \tilde{g}_{t}^{2} \\
& 1=\theta_{p}\left(\frac{\Pi_{t-1}^{\chi}}{\Pi_{t}}\right)^{1-\epsilon}+\left(1-\theta_{p}\right)\left(\Pi_{t}^{*}\right)^{1-\epsilon} \\
& m c_{t}=\left(\frac{1}{1-\alpha}\right)^{1-\alpha}\left(\frac{1}{\alpha}\right)^{\alpha} \tilde{w}_{t}^{1-\alpha} \tilde{r}_{t}^{\alpha} \\
& \frac{\tilde{k}_{t}}{l_{t}}=\frac{\alpha}{1-\alpha} \frac{\tilde{w}_{t}}{\tilde{r}_{t}} \\
& \tilde{y}_{t}=\frac{\frac{\hat{A}_{t}}{\hat{z}_{t}} A_{t}^{T}\left[\tilde{k}_{t-1}^{*} \exp \left(-d_{t} \theta_{t}\right)\right]^{\alpha} l_{t}^{1-\alpha}}{v_{t}^{p}} \\
& v_{t}^{p}=\theta_{p}\left(\frac{\Pi_{t-1}^{\chi}}{\Pi_{t}}\right)^{1-\epsilon} v_{t-1}^{p}+\left(1-\theta_{p}\right)\left(\Pi_{t}^{*}\right)^{1-\epsilon} \\
& \frac{R_{t}}{R}=\left(\frac{R_{t-1}}{R}\right)^{\gamma_{R}}\left(\left(\frac{\Pi_{t}}{\bar{\Pi}}\right)^{\gamma_{\Pi}}\left(\frac{\frac{\tilde{y}_{t}}{\tilde{y}_{t-1}} \hat{z}_{t}}{\exp \left(\Lambda_{y}\right)}\right)^{\gamma_{y}}\right)^{1-\gamma_{R}} e^{m_{t}} \\
& \tilde{y}_{t}=\tilde{c}_{t}+\tilde{x}_{t}
\end{aligned}
$$




$$
\begin{aligned}
\tilde{q}_{t}^{e} & =E_{t}\left(M_{t+1} \hat{z}_{t+1}\left(\tilde{d} v_{t+1}+\tilde{q}_{t+1}^{e}\right)\right) \\
\tilde{d i} v_{t} & =\tilde{y}_{t}-\tilde{w}_{t} l_{t}-\tilde{x}_{t} \\
\tilde{q}_{t}^{f} & =E_{t} M_{t+1}
\end{aligned}
$$

\section{Steady state}

To solve the steady state, the real wage $\tilde{w}$ solves equation $-\tilde{\lambda}_{t} \tilde{w}_{t}=(1-\psi) \tilde{U}_{t}^{-\psi} \tilde{U}_{l, t}$, while remaining variables are found recursively as follows:

$$
\begin{aligned}
& \Pi=\bar{\Pi} \\
& v^{p}=1 \\
& d=\mu^{d} \\
& \theta=\bar{\theta} \\
& \log \hat{A}=\Lambda_{A}-(1-\alpha) d \theta \\
& \log \hat{z}=\frac{1}{1-\alpha} \log \hat{A} \\
& \tilde{q}=1 \\
& M=\beta \hat{z}^{-\psi} \\
& \tilde{r}=\frac{\tilde{q}}{M \exp (-d \theta)}-\tilde{q}(1-\delta) \\
& \frac{\tilde{k}}{l}=\frac{\alpha}{1-\alpha} \frac{\tilde{w}}{\tilde{r}} \\
& \frac{\tilde{k}^{*}}{l}=\frac{\tilde{k}}{l} \exp \left(d_{t} \theta_{t}\right) \hat{z} \\
& l=\left(\phi+\frac{\tilde{w}}{\nu}\right)\left[\frac{\hat{A}}{\hat{z}}\left(\frac{\tilde{k}^{*}}{l} \exp (-d \theta)\right)^{\alpha}+\frac{\tilde{w}}{\nu}-\frac{\tilde{k}^{*}}{l}\left(1-\frac{(1-\delta)}{\hat{z}} \exp (-d \theta)\right)\right]^{-1} \\
& \tilde{k}^{*}=\frac{\tilde{k}^{*}}{l} l \\
& \tilde{k}=\frac{\tilde{k}^{*}}{\hat{z}} \exp (-d \theta) \\
& \tilde{x}=\tilde{k}^{*}-(1-\delta) \tilde{k} \\
& \tilde{c}=\frac{(1-l) \tilde{w}}{\nu}
\end{aligned}
$$




$$
\begin{aligned}
\tilde{y} & =\tilde{c}+\tilde{x} \\
\tilde{U} & =\tilde{c}(1-l)^{\nu} \\
U_{c} & =(1-l)^{\nu} \\
\tilde{\lambda} & =(1-\psi) \tilde{U}^{-\psi} U_{c} \\
S & =0 \\
S^{\prime} & =0 \\
\tilde{U}_{l} & =-\nu \tilde{c}(1-l)^{\nu-1} \\
\tilde{d i v} & =\tilde{y}-\tilde{w} l-\tilde{x} \\
\tilde{q}^{e} & =\frac{M \hat{z} d \tilde{i v}}{1-M \hat{z}} \\
\tilde{q}^{f} & =M_{t+1} \\
m c & =\left(\frac{1}{1-\alpha}\right)^{1-\alpha}\left(\frac{1}{\alpha}\right)^{\alpha} \tilde{w}^{1-\alpha} \tilde{r}^{\alpha} \\
R & =\frac{\Pi}{M} \\
\tilde{g}^{1} & =\frac{m c \tilde{y}}{1-\theta_{p} M \hat{z}} \\
\tilde{g}^{2} & =\frac{\epsilon}{\epsilon-1} \tilde{g}^{1} \\
\Pi^{*} & =\tilde{g}^{2} \frac{\left(1-\theta_{p} M \hat{z}\right)}{\tilde{y}}
\end{aligned}
$$

\section{The mechanics of disaster realizations and disaster risk}

This section briefly shows how disasters propagate in the model both via their actual realization (Section D.1) and via risk without their occurrence (Section D.2). The aim of this section is purely illustrative hence some simplifying assumptions are made, e.g. disasters hit

only permanent TFP (i.e. $\omega=1$ ) and occur once in 100 years (i.e. the annual probability of disasters is $\left.p_{d}^{\text {ann }}=0.01\right)$.

\section{D.1 Disaster realization}

Figure 7 reports relevant simulated variables for 100 years. The top-left panel shows the evolution of the disaster variables. While $\theta_{t}$ fluctuates over time, it affects productivity and output only in quarter 300, when the disaster occurs $\left(d_{t}=1\right)$. It follows that the level of TFP (bottom-left panel) drops and then returns to grow at the same rate as before the occurrence 
Figure 7: Simulated variables with a disaster realization.
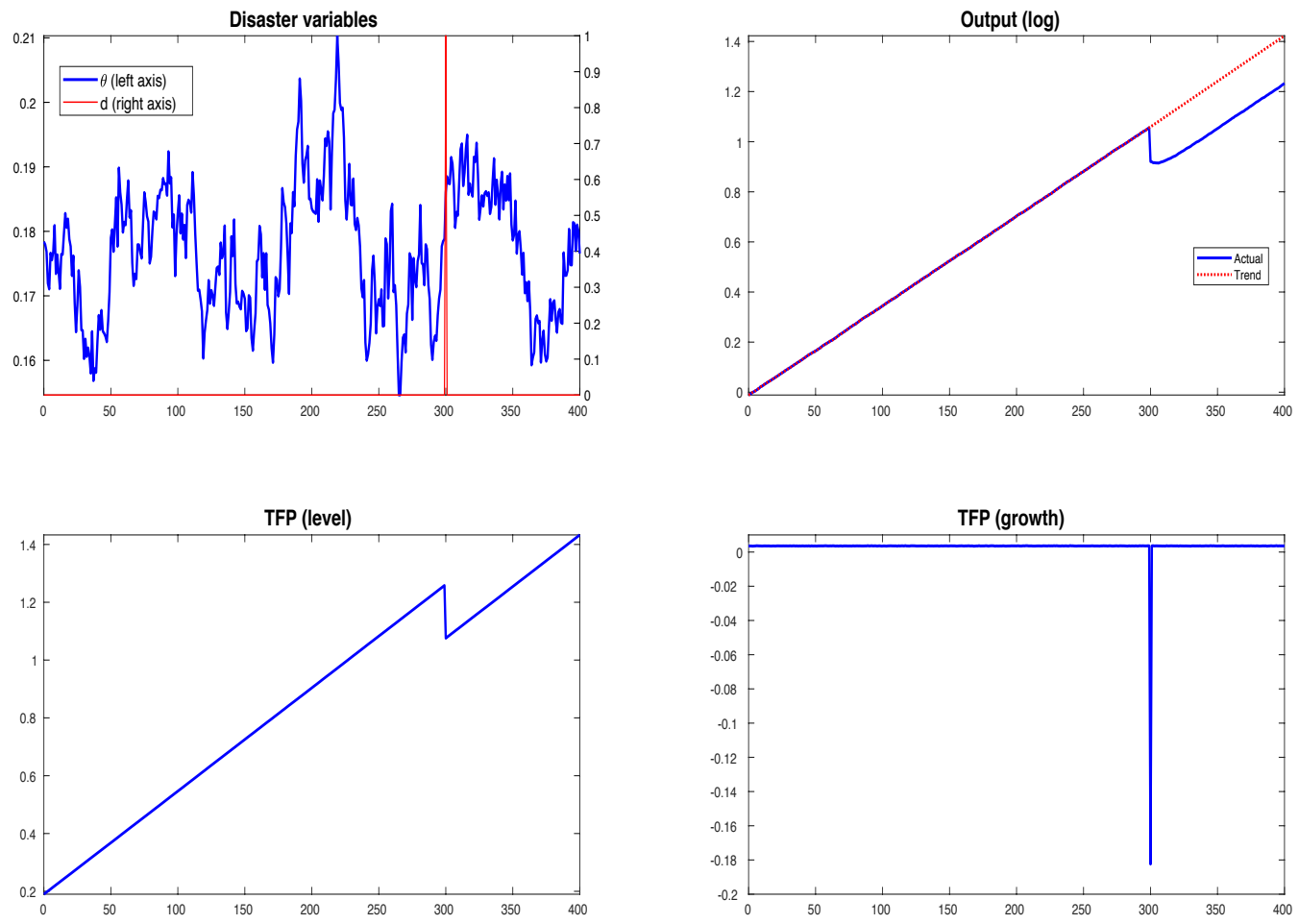

Notes: Selected variables simulated for 100 years, with a disaster shock occurring at period 300.

of the disaster, i.e. the growth rate of TFP is only temporarily affected (bottom-right panel). However, the effect on the level of TFP is permanent, i.e. the level is permanently lower than the level without the shock. Likewise, output (top-right panel) drops on impact and then grows again at the pre-disaster rate, thus its level is permanently affected. Assuming that also the stationary component of TFP is affected implies that, in the aftermath of the disaster, output and aggregate TFP would experience a period of higher growth thus generating a partial recovery. ${ }^{41}$

\section{D.2 Disaster risk}

In addition to the realization of the disaster, also the risk of it, without the realization of the event itself, affects the economy. While this risk shock is studied in Fernández-Villaverde and Levintal (2018), Gourio (2012) and Isoré and Szczerbowicz (2017), it takes slightly different specifications among them. Indeed, since Gourio (2012) and Isoré and Szczerbowicz (2017) allow for a time-varying probability of disasters, the risk shock entails an increase in this

\footnotetext{
${ }^{41}$ Nakamura et al. (2013) provide evidence that rare disasters are events with a large impact on GDP and consumption followed by partial recoveries, although they do not consider natural disasters.
} 
Figure 8: Impulse responses to a disaster risk shock.
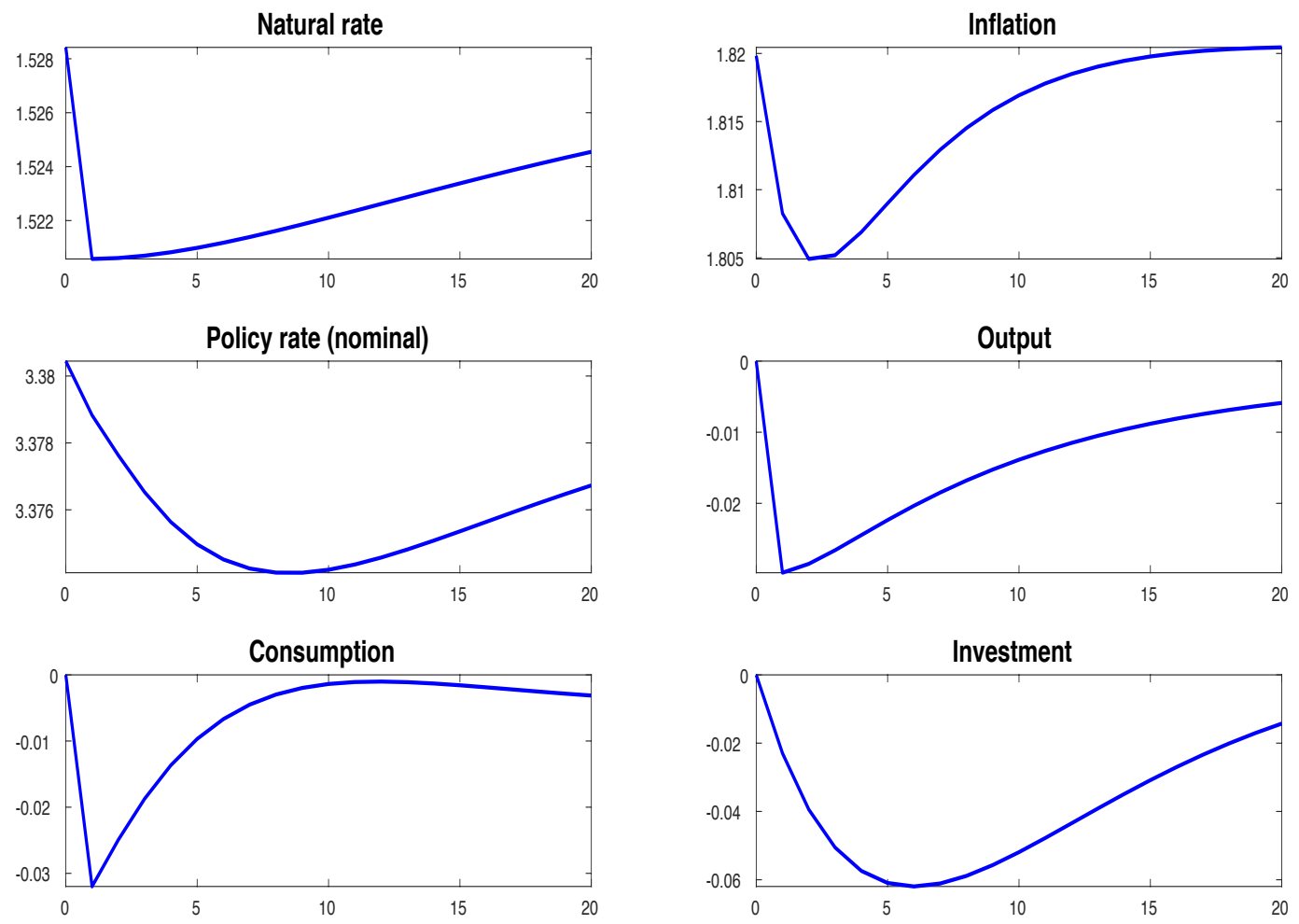

Notes: Impulse responses to a disaster risk shock, e.g. a temporary increase in expected damages to GDP, under the standard Taylor rule. Output, consumption and investment are expressed in percent deviations from the risk steady state. Inflation and interest rates are in percent annualized terms.

probability, e.g. agents perceive that a disaster is more likely to occur. Conversely, in Fernández-Villaverde and Levintal (2018) the probability is fixed (while the magnitude of the disaster is stochastic) hence the risk shock manifests itself in a higher expected impact of the disaster. Specifically, the risk shock entails a temporary increase in $\theta_{t}$ which, according to equation (3), decays at a rate governed by its persistence parameter $\rho_{\theta}$.

Crucially, risk affects agents' preferences thus shifting the economy from the deterministic to a stochastic (or risky) steady state (see proofs in Gourio (2012) and Isoré and Szczerbowicz (2017); and Coeurdacier et al. (2011) and Hills et al. (2019) for formal definitions of the risky steady state). Following Gourio (2012), it is possible to rewrite agents' discount factor $\beta$ as follows

$$
\tilde{\beta}=\beta\left[1-p_{d}\left(1-e^{-(1-\gamma) \log \bar{\theta}}\right)\right]^{\frac{1-\hat{\psi}}{(1-\gamma)(1+\nu)}},
$$

where $\tilde{\beta}$ is an equivalent discount factor. As long as the inverse of intertemporal elasticity of substitution $(\hat{\psi})$ is smaller than one, $\tilde{\beta}<\beta$ agents become more impatient and invest less. The economy thus shifts to a lower steady state (the risky steady state). Moreover, as already 
discussed in Gourio (2012) and Isoré and Szczerbowicz (2017), risk entails a mix of first and second moment effects. Indeed, agents expect lower productivity, higher depreciation and lower return on capital thus invest less and a recession occur. This is the first moment effect. In addition, uncertainty about the disaster realization and, conditional on its occurrence, on the size of the disaster generates a recession. This is the second moment effect. To show how a risk shock propagates in the model, Figure 8 reports impulse responses of output, consumption, investment (all detrended), inflation, policy and natural interest rates, when agents expected the average GDP loss to increase from the average in the data (2.95\%) to its $97.5^{\text {th }}$ percentile $(11.8 \%)$. This shock, without the occurrence of the disaster itself, suffices to trigger a recession and a fall in inflation. Moreover, higher demand of risk-free bonds induced by precautionary savings generates a fall in the natural rate. ${ }^{42}$ The magnitude of these responses are nevertheless in line with Fernández-Villaverde and Levintal (2018). They simulate an increase of the average GDP loss from $40 \%$ to $45 \%$ and find that output at the trough is $0.015 \%$ below its stochastic steady state. ${ }^{43}$

\section{E Sensitivity analysis}

In this section we discuss sensitivity analysis on uncertain parameters, both ex-ante and ex-post. Qualitatively, the main results of the paper carry through the various sensitivities. Some parameters have a stronger quantitative effect and are discussed more in detail. All sensitivities are conducted under the standard Taylor rule, unless otherwise stated.

\section{E.1 Ex-ante}

Table 6 shows the sensitivity of the risky steady states of the natural rate and inflation to preference parameters and the disaster process (3). The first column reports the baseline results for comparison. The second and third columns report two cases that are extracted from Figure 3. Lowering the risk aversion coefficient to equal the inverse of the IES keeps the natural rate and inflation higher than in the baseline hence the model would not capture any ex-ante effect of natural disasters. Increasing the inverse of the intertemporal elasticity of substitution $\hat{\psi}$ to 2 , the value used by Isoré and Szczerbowicz (2017), increases the natural rate while lowering inflation because agents require a higher interest rate in order to save. Changing the standard deviation of the disaster risk shock $\left(\sigma_{\theta}\right)$ affects the distribution of

\footnotetext{
${ }^{42}$ One key parameter determining the magnitude of these responses is risk aversion $\gamma$. Obviously, higher risk aversion amplifies the responses, especially that of the natural rate.

${ }^{43}$ Magnitudes are also of the same order as in Isore and Szczerbowicz (2017) despite the different modeling of the disaster risk shock.
} 
Table 6: Risky steady states under alternative calibrations of preferences and disaster process.

\begin{tabular}{ccccccc}
\hline \multicolumn{7}{c}{ Risky Steady State } \\
\hline & Baseline & \multicolumn{3}{c}{ Preferences } & \multicolumn{3}{c}{ Disaster process } \\
\hline \multirow{3}{*}{ Natural rate } & 1.55 & $\gamma=0.5$ & $\hat{\psi}=2$ & $\sigma_{\theta}=0$ & $\sigma_{\theta}=0.5$ & $\rho_{\theta}=0$ \\
Inflation & 1.56 & 1.87 & 2.39 & 1.55 & 1.54 & 1.55 \\
& 1.85 & 1.87 & 1.72 & 1.87 \\
\hline
\end{tabular}

Notes: Risky steady state of the natural rate and inflation under the standard Taylor rule and alternative calibrations of preferences and disaster process. The risky steady state is calculated by simulating the model for 100 periods without shocks. Inflation and interest rates are in \% annualized values. The central bank's inflation target is $1.9 \%$. Baseline calibration: $\gamma=7 ; \hat{\psi}=0.5 ; \sigma_{\theta}=0.22 ; \rho_{\theta}=0.95$.

disasters but has a larger effect on inflation rather than the natural rate, as reported in the fourth and fifth columns of Table 6. Finally, making the disaster risk shock i.i.d. $\left(\rho_{\theta}=0\right.$, last column) slightly increases inflation. Sensitivity on other parameters (persistence of the stationary TFP process, Taylor rule, price stickiness and investment adjustment costs) barely affect the results hence are not reported. ${ }^{44}$

Next, Figure 9 repeats the same exercise as in Figure 2, however under the inflation targeting regime. Specifically, the risky steady state of the natural rate and inflation are reported for a range of average disasters while keeping the annual probability fixed at $2.2 \%$ (left plot), and for a range of annual probabilities while keeping the average disaster size at $2.95 \%$ of GDP (right plot). While the natural rate is exactly the same as in Figure 2 because monetary policy is neutral in a flexible price world, inflation only slightly decreases as the average size or probability increase, hence the central bank manages to keep it close to the target.

Finally, we show how the stochastic steady state is affected by the assumption about the distribution of natural disasters on TFP (e.g. for different values of $\omega$ ) in Table 7 . The first column reports the baseline case when the effects are equally distributed, while the second and third columns show the two extreme cases of only permanent effects of natural disasters (second column) and only temporary effects (third column). Not surprisingly, the larger (smaller) the effects on permanent TFP, the smaller (bigger) are inflation and the natural rate.

\footnotetext{
${ }^{44}$ These are available upon request. Nevertheless, repeating these sensitivities for a more extreme scenario leads to larger differences relative to the baseline, although it is still preference parameters that have the largest impact.
} 
Figure 9: Risky steady state of natural rate and inflation for different average disaster size and annual probability under inflation targeting.
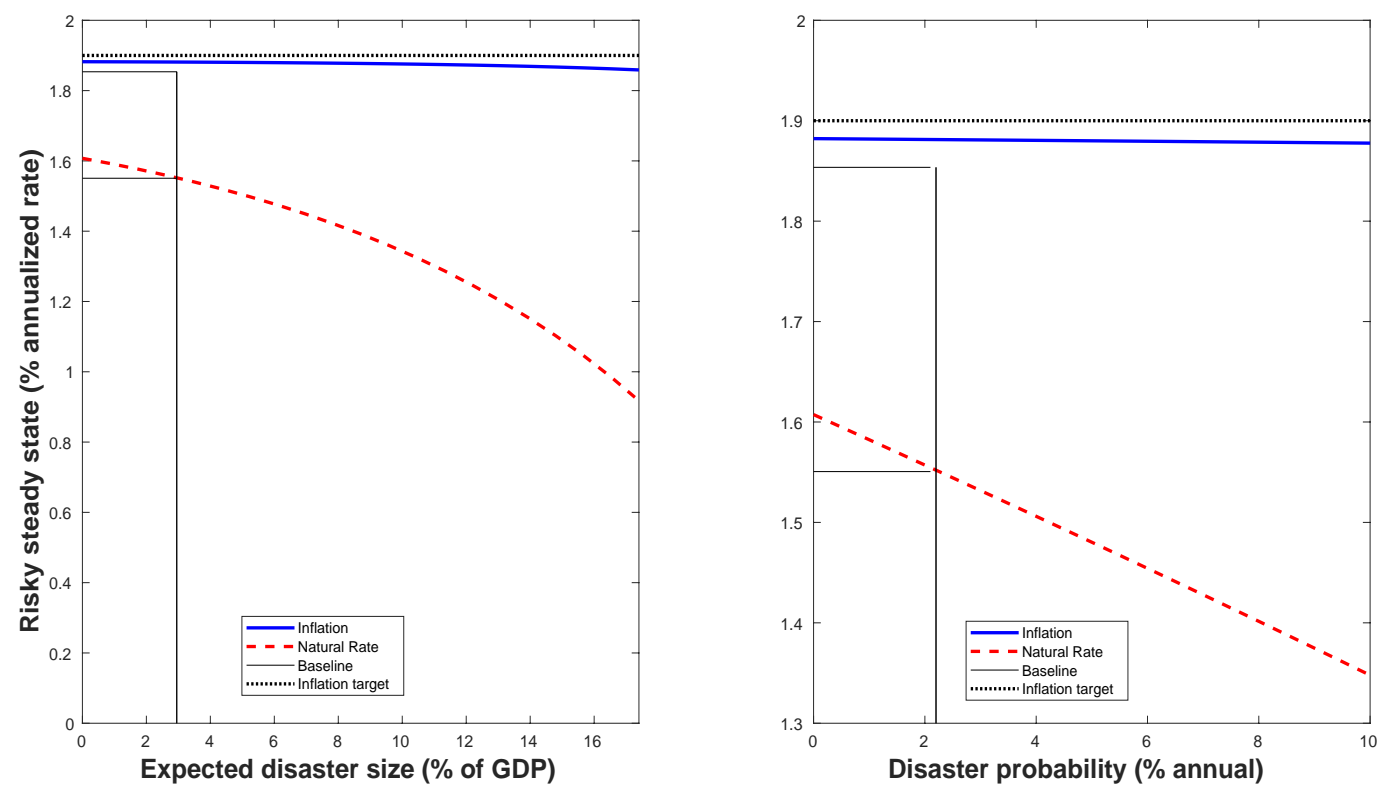

Notes: Risky steady state of the natural rate and inflation under the strict inflation targeting regime for different average disaster size (with fixed annual probability at $2.2 \%$, left plot) and annual probability (with fixed average damages at $2.95 \%$ of GDP, right plot). The risky steady state is calculated by simulating the model for 100 periods without shocks. Inflation and interest rates are in $\%$ annualized values. The central bank's inflation target is $1.9 \%$.

\section{E.2 Ex-post}

Figure 10 plots the impulse responses to the average disaster under alternative assumption of the impact on the two components of productivity. As expected, the larger the impact on the permanent component of productivity (i.e. larger $\omega$ ) the more persistent are the effects of natural disasters. In the extreme case of effects only on permanent TFP (i.e. $\omega=1$ ), the effects are clearly permanent. Conversely, as the effect becomes larger on the stationary component of TFP (i.e. smaller $\omega$ ), productivity partially recovers to the pre-disaster level as also the other macro variables do. In the extreme case of $\omega=0$, the impact of disasters is only temporary. As regards the natural rate, the increase is much smaller when only the permanent component of TFP is affected by disasters. The intuition behind these results is that productivity and physical capital are permanently (or very persistently) dampened by the disaster hence investment rises less. It follows that inflation stabilizes below target hence the central bank has room to accommodate an increase in the aftermath of the rare event.

To investigate the role of disaster risk persistence on the ex-post effects of disasters, 
Table 7: Risky steady states under different distributions of disasters on productivity.

\begin{tabular}{|c|c|c|c|}
\hline \multicolumn{4}{|c|}{ Risky Steady State } \\
\hline & $\begin{array}{l}\text { Half on perm. TFP } \\
\qquad \omega=0.5\end{array}$ & $\begin{array}{l}\text { All on perm. TFP } \\
\qquad \omega=1\end{array}$ & $\begin{array}{l}\text { All on temp. TFP } \\
\qquad \omega=0\end{array}$ \\
\hline \multicolumn{4}{|c|}{ (i) Average disaster $\left(p_{d}^{a n n}=2.2 \%\right.$; Damages to $\left.G D P=2.95 \%\right)$} \\
\hline Natural rate & 1.55 & 1.53 & 1.57 \\
\hline Inflation & 1.85 & 1.82 & 1.87 \\
\hline \multicolumn{4}{|c|}{ (ii) Extreme disaster $\left(p_{d}^{a n n}=0.05 \%\right.$; Damages to $\left.G D P=11.8 \%\right)$} \\
\hline Natural rate & 1.60 & 1.59 & 1.60 \\
\hline Inflation & 1.87 & 1.85 & 1.88 \\
\hline \multicolumn{4}{|c|}{ (iii) Extreme disaster - worst scenario $\left(p_{d}^{a n n}=2.2 \%\right.$; Damages to $G D P=11.8 \%$} \\
\hline Natural rate & 1.26 & 1.08 & 1.44 \\
\hline Inflation & 1.48 & 0.57 & 1.81 \\
\hline
\end{tabular}

Notes: Risky steady state of the natural rate and inflation under the standard Taylor rule and alternative calibrations of the distribution of disasters on permanent and temporary TFP. The risky steady state is calculated by simulating the model for 100 periods without shocks. Inflation and interest rates are in \% annualized values. The central bank's inflation target is $1.9 \%$.

Figure 11 reports the impulse responses under the baseline calibration with high persistence ( $\rho_{\theta}=0.95$, blue-solid lines) and no persistence $\left(\rho_{\theta}=0\right.$, red-dotted lines). Clearly, lower persistence only changes the risky steady state of inflation and the policy rate while leaving the dynamics after the disaster unaffected.

Finally, the dynamics after a disaster, in particular that of inflation and the policy rate, may be affected by the degree of price rigidities in the economy. Figure 12 shows the impulse responses to an average disaster shock under the baseline calibration of price rigidities $\left(\theta_{p}=\right.$ $0.905, \chi=0.472$, blue-solid lines) where prices last on average for 10 quarters, and two alternative calibrations. One in which price stickiness is diminished to $\theta_{p}=0.60$ meaning that on average prices last for 2.5 quarters, while keeping the same degree of price indexation $\left(\theta_{p}=0.60, \chi=0\right.$, red-dotted lines). The other removes price indexation in addition to lower price stickiness (black-dashed lines). Impulse responses show that lower price rigidities make inflation react much stronger on impact and increasing well above the target. This requires a strong tightening of monetary policy, where the policy rate is immediately increased. However, output, consumption and investment are only slightly affected by the tighter policy. 
Figure 10: Impulse responses to an average disaster shock under alternative distribution of disasters on permanent and transitory productivity.
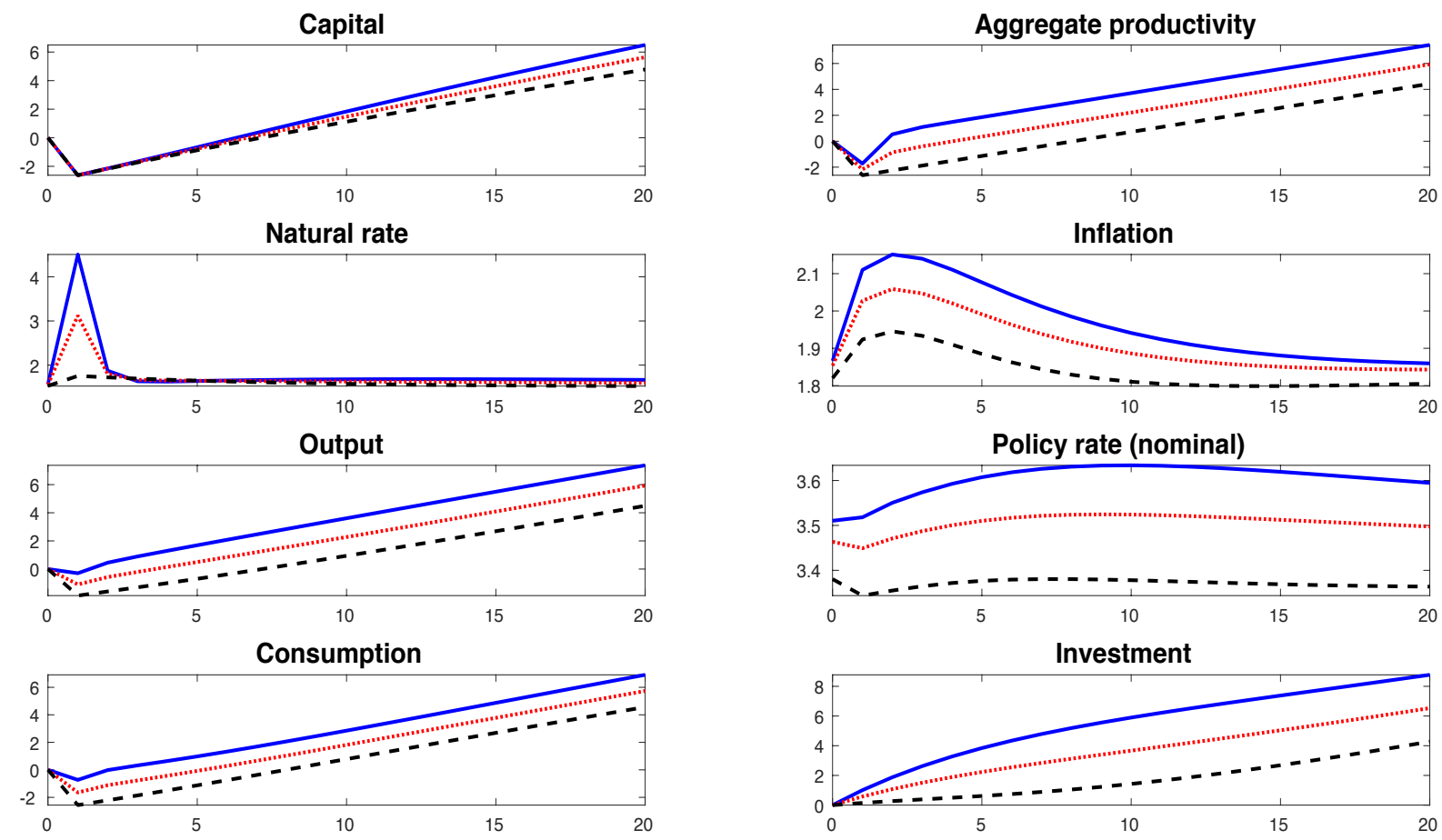

$-\omega=0 \quad \cdots \cdots \cdots \cdots \omega=0.50 \quad--\omega=1$

Notes: Impulse responses to an average disaster shock equal to $2.95 \%$ of GDP under the standard Taylor rule and under alternative distribution of disasters on permanent and transitory productivity. Output, consumption, investment, capital and productivity are expressed in non-stationary form and in percent deviations from the risk steady state. The risky steady state is calculated by simulating the model for 100 periods without shocks. Inflation and interest rates are in percent annualized terms. For $\omega=0$, disasters hit only stationary TFP. For $\omega=1$, disasters hit only permanent TFP. For $\omega=0.50$, disasters are equally distributed on both components of TFP.

\section{F Demand-side effects of disaster realizations: an alter- native channel}

Alternatively to allowing for temporarily higher risk aversion described in Section 5.2.2, we introduce a simple risk-premium shock linked to the realization of rare disasters. Starting from Smets and Wouters (2007), this shock has been widely used in New-Keynesian models to generate business cycle comovement among macroeconomic variables. This type of shock can be interpreted as a structural shock for demand of safe and liquid assets (Fisher, 2015) and has been used also in the literature on the natural interest rate (see e.g. Barsky et al., 2014 and Neri and Gerali, 2017) to capture the effects of higher demand for safe assets in the 
Figure 11: Impulse responses to an average disaster shock under alternative calibrations of disaster risk persistence.
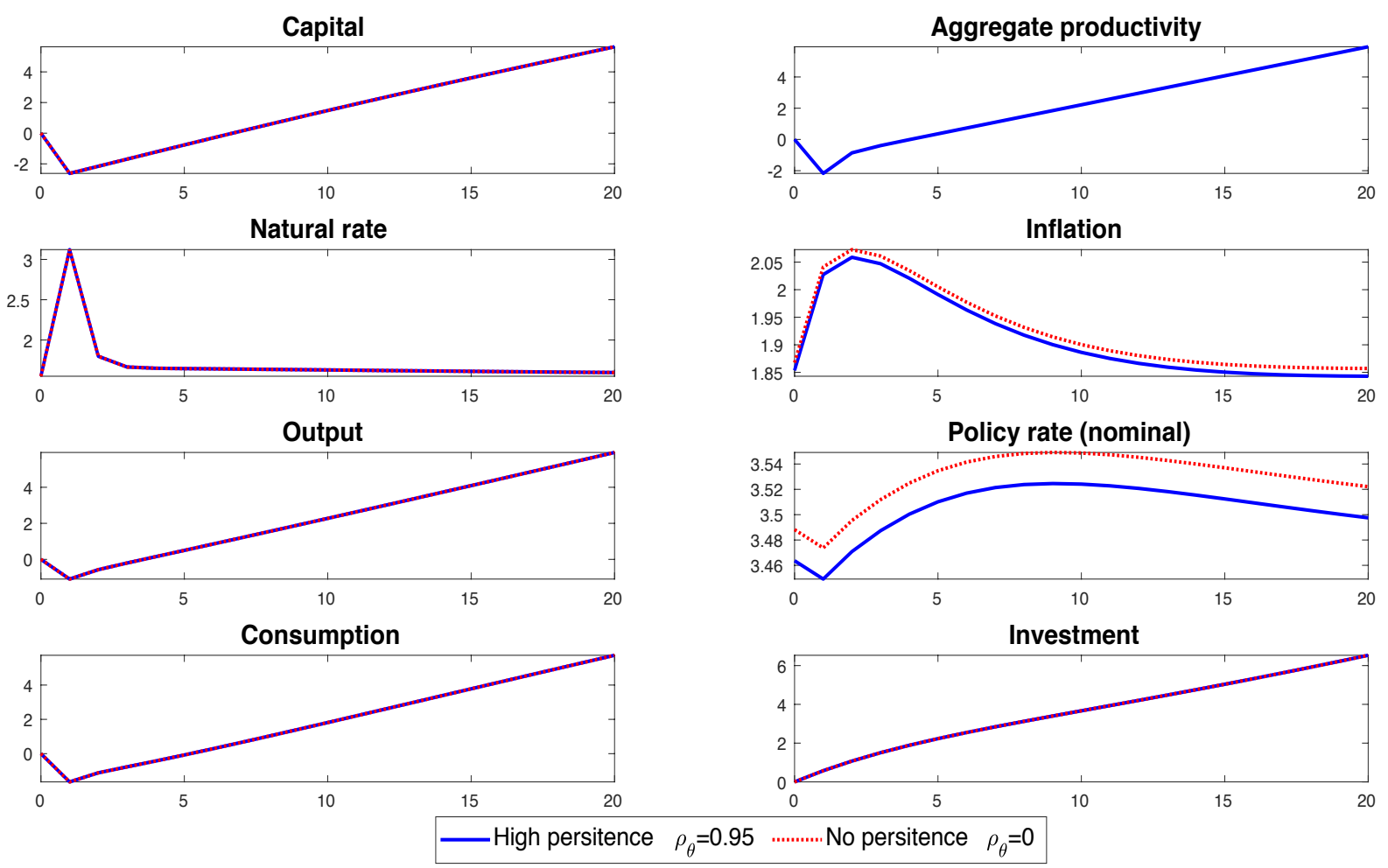

Notes: Impulse responses to an average disaster shock equal to $2.95 \%$ of GDP under the standard Taylor rule and under three alternative calibration of the persistence of the disaster risk shock (equation 3). Output, consumption, investment, capital and productivity are expressed in non-stationary form and in percent deviations from the risk steady state. The risky steady state is calculated by simulating the model for 100 periods without shocks. Inflation and interest rates are in percent annualized terms.

aftermath of the global financial crisis. Moreover, models of rare disasters (see e.g. Barro, 2006; Gabaix, 2012; Gourio, 2012 and Isoré and Szczerbowicz, 2017) introduce this type of shock to allow for partial defaults on government bonds, i.e. conditional on the realization of disasters, the stock of bonds is lower due to the default thus causing a drop in the price and an increase in the rate of return. The model is therefore modified as follows. The household's budget constraint (8) now reads as:

$$
c_{t}+x_{t}+b_{t+1}=w_{t} l_{t}+r_{t} k_{t}+R_{t-1} b_{t} e^{\zeta \log \tau_{t}}+F_{t}+T_{t},
$$

where the risk premium shock is triggered by disasters and follows a $\mathrm{AR}(1)$ process:

$$
\log \tau_{t}=\left(1-\rho_{\tau}\right) \log \tau+\rho_{\tau} \log \tau_{t-1}+d_{t} \theta_{t}
$$


Figure 12: Impulse responses to an average disaster shock under alternative calibrations of price stickiness and indexation.
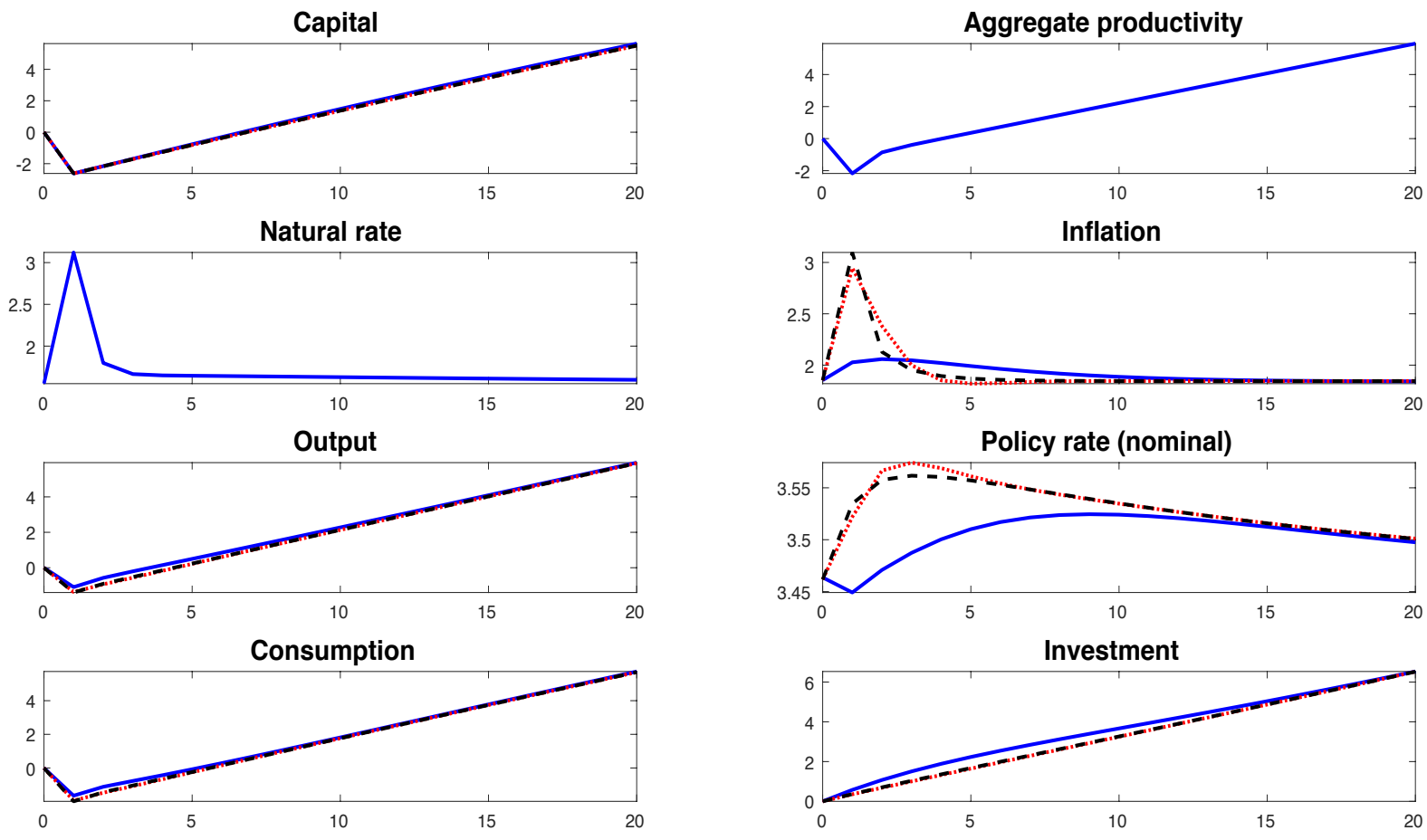

Baseline ........... Lower price stickiness - - - Lower price stickiness + no indexation

Notes: Impulse responses to an average disaster shock equal to $2.95 \%$ of GDP under the standard Taylor rule and under alternative distribution of disasters on permanent and transitory productivity. Output, consumption, investment, capital and productivity are expressed in non-stationary form and in percent deviations from the risk steady state. The risky steady state is calculated by simulating the model for 100 periods without shocks. Inflation and interest rates are in percent annualized terms. Baseline: $\theta_{p}=$ $0.905, \chi=0.472$. Lower price stickiness: $\theta_{p}=0.60, \chi=0.472$. Lower price stickiness + no indexation: $\theta_{p}=0.60, \chi=0$.

It follows that two parameters determine the amplification effects of the risk premium shock: the elasticity of the interest rate to disasters $(\zeta)$ and the persistence of the risk premium shock $\left(\rho_{\tau}\right)$. Given the budget constraint (98), the Euler equation (9) now reads as:

$$
1=E_{t}\left[M_{t+1} \frac{R_{t}}{\prod_{t+1}} e^{\zeta \log \tau_{t}}\right]
$$

Obviously, there is large uncertainty around the two parameters $\zeta$ and $\rho_{\tau}$. Figure 13 reports the impulse responses to an average disaster shock in the baseline model (black-solid lines) where there is no risk premium $(\zeta=0)$ and in a model with a risk premium on bonds (red-dotted lines). As an illustration, the risk premium shock is assumed to be persistent $\left(\rho_{\tau}=0.85\right)$ with an elasticity of $\zeta=0.5$. This combination of parameters leads to a substan- 
Figure 13: Impulse responses to an average disaster shock under with and without the risk premium channel.
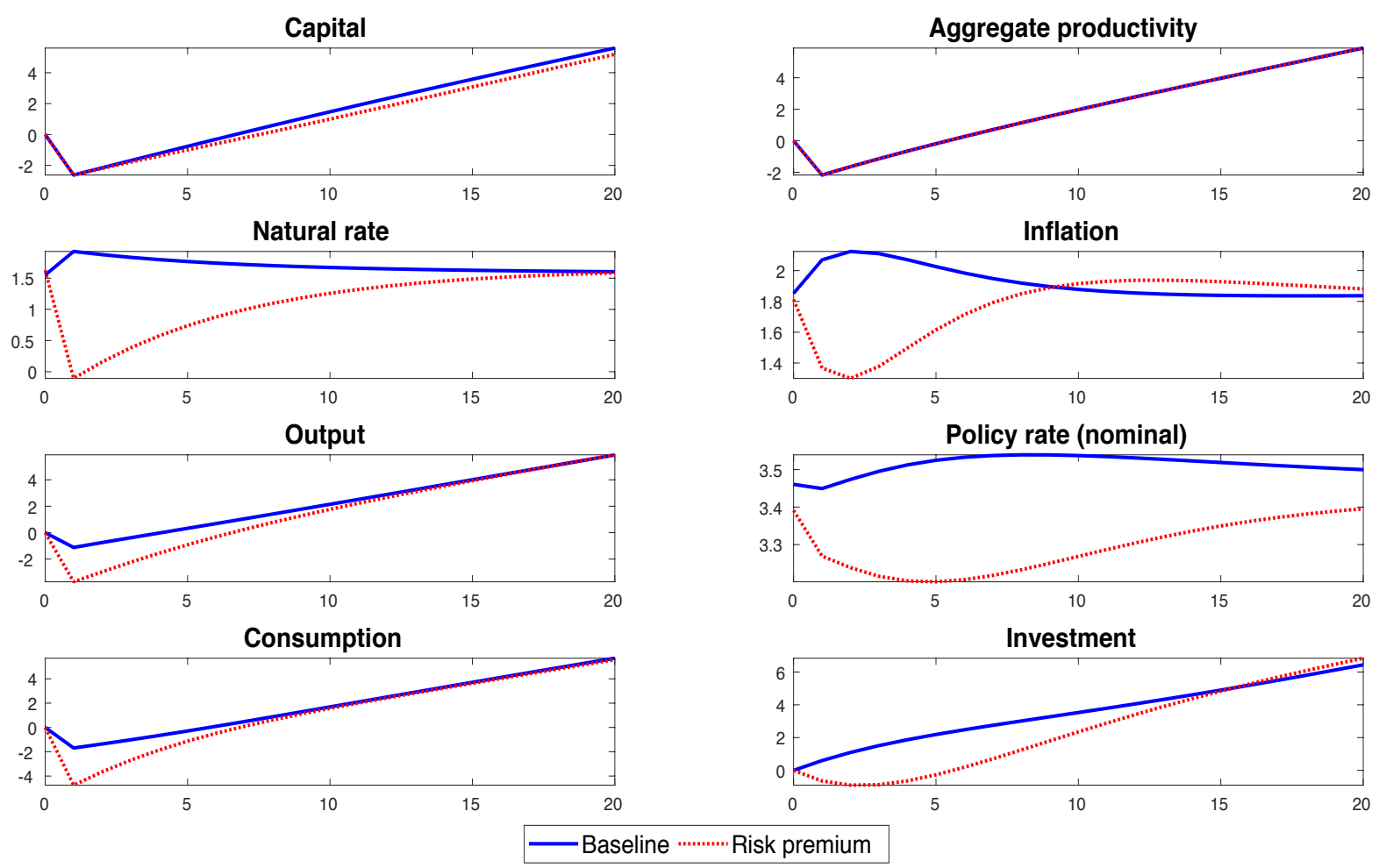

Impulse responses to an average disaster shock equal to $2.95 \%$ of GDP under the standard Taylor rule, when the risk premium shock is not activated (blue-solid lines), and when it is activated (red-dotted lines). Output, consumption, investment, capital and productivity are expressed in non-stationary form and in percent deviations from the risk steady state. The risky steady state is calculated by simulating the model for 100 periods without shocks. Inflation and interest rates are in percent annualized terms.

tial amplification of the real effects of an average disaster, with output, consumption and investment falling more than in the baseline. Capital and aggregate productivity are the same, at least on impact, because the shock is the same across the two models. However, since with a risk premium investment is discouraged, in the long run the capital stock is lower than in the model without the risk premium channel. Moreover, inflation falls before slightly overshooting the target after about 10 quarters. Finally, the natural rate falls below zero upon impact before converging back to the pre-disaster level. While this combination of parameters shows that it is possible to generate demand effects from supply shocks, there exist other parameters values according to which the supply channel still prevails. In particular, Figure 14 shows different combinations of the two parameters generate (blue dots) or not (red dots) a stronger demand effect, with natural rate and inflation falling for at least 
Figure 14: Combinations of parameters that generate demand effects with risk premium shock. Red dots: supply effects prevails. Blue dots: demand effects prevail.

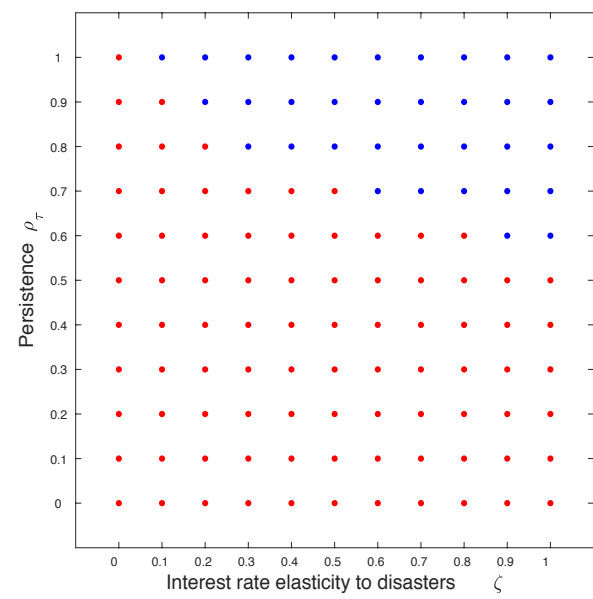

Notes: Blue dots: natural rate and inflation fall for at least two quarters after the disaster. Red dots: natural rate and/or inflation increase after the shock or they fall for only one quarter.

two quarters after the disaster. ${ }^{45}$

${ }^{45}$ This criterion used to discriminate between the two effects is obviously arbitrary. A tighter one would shrink the parameter space that generates demand effects while a looser one would enlarge it. 


\section{RECENTLY PUBLISHED “TEMI” (*)}

N.1287 - Court efficiency and aggregate productivity: the credit channel, by Guzmán González-Torres and Giacomo Rodano (July 2020).

N. 1288 - The time-varying risk of Italian GDP, by Fabio Busetti, Michele Caivano, Davide Delle Monache and Claudia Pacella (July 2020).

N.1289 - Trade shocks and credit reallocation, by Stefano Federico, Fadi Hassan and Veronica Rappoport (July 2020).

N. 1290 - The impact of the IRB approach on the relationship between the cost of credit for public companies and financial market conditions, by Raffaele Gallo (July 2020).

N. 1291 - An economic assessment of the evolution of the corporate tax system in Italy, by Ernesto Zangari (September 2020).

N.1292 - Asymmetric information in corporate lending: evidence from SME bond markets, by Alessandra Iannamorelli, Stefano Nobili, Antonio Scalia and Luana Zaccaria (September 2020).

N. 1293 - Fiscal space and the size of fiscal multiplier, by Luca Metelli and Kevin Pallara (September 2020).

N.1294 - Prudential policies, credit supply and house prices: evidence from Italy, by Pierluigi Bologna, Wanda Cornacchia and Maddalena Galardo (September 2020).

N. 1295 - How loose, how tight? A measure of monetary and fiscal stance for the euro area, by Nicoletta Batini, Alessandro Cantelmo, Giovanni Melina and Stefania Villa (September 2020).

N. 1296 - Price dividend ratio and long-run stock returns: a score driven state space model, by Davide Delle Monache, Ivan Petrella and Fabrizio Venditti (September 2020).

N.1297 - Workforce aging, pension reforms, and firm outcomes, by Francesca Carta, Francesco D'Amuri and Till von Wachter (September 2020).

N. 1298 - Anti-poverty measures in Italy: a microsimulation analysis, by Nicola Curci, Giuseppe Grasso, Pasquale Recchia and Marco Savegnago (September 2020).

N. 1299 - Forecasting US recessions: the role of economic uncertainty, by Valerio Ercolani and Filippo Natoli (September 2020).

N.1300 - Demographics and the natural real interest rate: historical and projected paths for the euro area, by Andrea Papetti (November 2020).

N.1301 - A quantitative analysis of distortions in managerial forecasts, by Yueran Ma, Tiziano Ropele, David Sraer and David Thesmar (November 2020).

N. 1302 - Bargaining power and the Phillips curve: a micro-macro analysis, by Marco J. Lombardi, Marianna Riggi and Eliana Viviano (November 2020).

N. 1303 - The effects of structural reforms: Evidence from Italy, by Emanuela Ciapanna, Sauro Mocetti and Alessandro Notarpietro (November 2020).

N. 1304 - Consumption and Wealth: New Evidence from Italy, by Riccardo De Bonis, Danilo Liberati, John Muellbauer and Concetta Rondinelli (November 2020).

N. 1305 - Do details matter? An analysis of the Italian personal income tax, by Martino Tasso (November 2020).

N. 1306 - Effects of eligibility for central bank purchases on corporate bond spreads, by Taneli Mäkinen, Fan Li, Andrea Mercatanti and Andrea Silvestrini (November 2020).

(*) Requests for copies should be sent to:

Banca d'Italia - Servizio Studi di struttura economica e finanziaria - Divisione Biblioteca e Archivio storico - Via Nazionale, 91 - 00184 Rome - (fax 003906 47922059). They are available on the Internet www.bancaditalia.it. 
Accetturo A., V. Di Giacinto, G. Micucci and M. Pagnini, Geography, productivity and trade: does selection explain why some locations are more productive than others?, Journal of Regional Science, v. 58, 5, pp. 949-979, WP 910 (April 2013).

ADAMOPOULOU A. and E. KAYA, Young adults living with their parents and the influence of peers, Oxford Bulletin of Economics and Statistics,v. 80, pp. 689-713, WP 1038 (November 2015).

Andini M., E. Ciani, G. De Blasio, A. D’Ignazio and V. Silvestrini, Targeting with machine learning: an application to a tax rebate program in Italy, Journal of Economic Behavior \& Organization, v. 156, pp. 86-102, WP 1158 (December 2017).

BARONE G., G. DE BLASIO and S. MOCETTI, The real effects of credit crunch in the great recession: evidence from Italian provinces, Regional Science and Urban Economics, v. 70, pp. 352-59, WP 1057 (March 2016).

Belotti F. and G. IlARDi Consistent inference in fixed-effects stochastic frontier models, Journal of Econometrics, v. 202, 2, pp. 161-177, WP 1147 (October 2017).

Berton F., S. Mocetti, A. Presbitero and M. Richiardi, Banks, firms, and jobs, Review of Financial Studies, v.31, 6, pp. 2113-2156, WP 1097 (February 2017).

Bofondi M., L. CARPinelli and E. SETte, Credit supply during a sovereign debt crisis, Journal of the European Economic Association, v.16, 3, pp. 696-729, WP 909 (April 2013).

Bokan N., A. Gerali, S. Gomes, P. JACQuinOt and M. PiSANI, EAGLE-FLI: a macroeconomic model of banking and financial interdependence in the euro area, Economic Modelling, v. 69, C, pp. 249280, WP 1064 (April 2016).

BRILli Y. and M. TONELlo, Does increasing compulsory education reduce or displace adolescent crime? New evidence from administrative and victimization data, CESifo Economic Studies, v. 64, 1, pp. 15-4, WP 1008 (April 2015).

BUONO I. and S. FORMAI The heterogeneous response of domestic sales and exports to bank credit shocks, Journal of International Economics, v. 113, pp. 55-73, WP 1066 (March 2018).

Burlon L., A. Gerali, A. NotarPietro and M. Pisani, Non-standard monetary policy, asset prices and macroprudential policy in a monetary union, Journal of International Money and Finance, v. 88, pp. 25-53, WP 1089 (October 2016).

CARTA F. and M. DE PHLIPPIS, You've Come a long way, baby. Husbands' commuting time and family labour supply, Regional Science and Urban Economics, v. 69, pp. 25-37, WP 1003 (March 2015).

CARTA F. and L. RIZZICA, Early kindergarten, maternal labor supply and children's outcomes: evidence from Italy, Journal of Public Economics, v. 158, pp. 79-102, WP 1030 (October 2015).

Casiraghi M., E. Gaiotti, L. Rodano and A. SECchi, A “Reverse Robin Hood"? The distributional implications of non-standard monetary policy for Italian households, Journal of International Money and Finance, v. 85, pp. 215-235, WP 1077 (July 2016).

CIANI E. and C. DEIANA, No Free lunch, buddy: housing transfers and informal care later in life, Review of Economics of the Household, v.16, 4, pp. 971-1001, WP 1117 (June 2017).

Cipriani M., A. Guarino, G. Guazzarotti, F. Tagliati and S. Fisher, Informational contagion in the laboratory, Review of Finance, v. 22, 3, pp. 877-904, WP 1063 (April 2016).

De Blasio G, S. De Mitri, S. D’Ignazio, P. Finaldi Russo and L. Stoppani, Public guarantees to SME borrowing. A RDD evaluation, Journal of Banking \& Finance, v. 96, pp. 73-86, WP 1111 (April 2017).

Gerali A., A. LocARno, A. NotARPIETRO and M. PISANI, The sovereign crisis and Italy's potential output, Journal of Policy Modeling, v. 40, 2, pp. 418-433, WP 1010 (June 2015).

LIBERATI D., An estimated DSGE model with search and matching frictions in the credit market, International Journal of Monetary Economics and Finance (IJMEF), v. 11, 6, pp. 567-617, WP 986 (November 2014).

LinAREllo A., Direct and indirect effects of trade liberalization: evidence from Chile, Journal of Development Economics, v. 134, pp. 160-175, WP 994 (December 2014).

NAtoli F. and L. SigAlotTi, Tail co-movement in inflation expectations as an indicator of anchoring, International Journal of Central Banking, v. 14, 1, pp. 35-71, WP 1025 (July 2015).

NuCCI F. and M. RigGI, Labor force participation, wage rigidities, and inflation, Journal of Macroeconomics, v. 55, 3 pp. 274-292, WP 1054 (March 2016).

RIGON M. and F. ZANETTI, Optimal monetary policy and fiscal policy interaction in a non_ricardian economy, International Journal of Central Banking, v. 14 3, pp. 389-436, WP 1155 (December 2017). 
SEGURA A., Why did sponsor banks rescue their SIVs?, Review of Finance, v. 22, 2, pp. 661-697, WP 1100 (February 2017).

AlbANESE G., M. CIOFFI and P. TOMMASINO, Legislators' behaviour and electoral rules: evidence from an Italian reform, European Journal of Political Economy, v. 59, pp. 423-444, WP 1135 (September 2017).

Aprigliano V., G. ArdizzI and L. MonTEForte, Using the payment system data to forecast the economic activity, International Journal of Central Banking, v. 15, 4, pp. 55-80, WP 1098 (February 2017).

ARNAUdo D., G. MiCUCCI, M. RigON and P. Rossi, Should I stay or should I go? Firms' mobility across banks in the aftermath of the financial crisis, Italian Economic Journal / Rivista italiana degli economisti, v. 5, 1, pp. 17-37, WP 1086 (October 2016).

BASSO G., F. D’AMURI and G. PERI, Immigrants, labor market dynamics and adjustment to shocks in the euro area, IMF Economic Review, v. 67, 3, pp. 528-572, WP 1195 (November 2018).

BAtini N., G. MelinA and S. Villa, Fiscal buffers, private debt, and recession: the good, the bad and the ugly, Journal of Macroeconomics, v. 62, WP 1186 (July 2018).

Burlon L., A. Notarpietro and M. Pisani, Macroeconomic effects of an open-ended asset purchase programme, Journal of Policy Modeling, v. 41, 6, pp. 1144-1159, WP 1185 (July 2018).

Busetti F. and M. CAIVANO, Low frequency drivers of the real interest rate: empirical evidence for advanced economies, International Finance, v. 22, 2, pp. 171-185, WP 1132 (September 2017).

CAppelletti G., G. GuAzZAROtTi and P. TOMmasino, Tax deferral and mutual fund inflows: evidence from a quasi-natural experiment, Fiscal Studies, v. 40, 2, pp. 211-237, WP 938 (November 2013).

CARDANi R., A. PACCAGNINI and S. VILla, Forecasting with instabilities: an application to DSGE models with financial frictions, Journal of Macroeconomics, v. 61, WP 1234 (September 2019).

Chiades P., L. Greco, V. Mengotto, L. Moretti and P. Valbonesi, Fiscal consolidation by intergovernmental transfers cuts? The unpleasant effect on expenditure arrears, Economic Modelling, v. 77, pp. 266-275, WP 1076 (July 2016).

CIANI E., F. DAVID and G. DE BLASIO, Local responses to labor demand shocks: a re-assessment of the case of Italy, Regional Science and Urban Economics, v. 75, pp. 1-21, WP 1112 (April 2017).

CIANI E. and P. FISHER, Dif-in-dif estimators of multiplicative treatment effects, Journal of Econometric Methods, v. 8. 1, pp. 1-10, WP 985 (November 2014).

CIAPANNA E. and M. TABOGA, Bayesian analysis of coefficient instability in dynamic regressions, Econometrics, MDPI, Open Access Journal, v. 7, 3, pp.1-32, WP 836 (November 2011).

Coletta M., R. De Bonis and S. PIERMATteI, Household debt in OECD countries: the role of supply-side and demand-side factors, Social Indicators Research, v. 143, 3, pp. 1185-1217, WP 989 (November 2014).

Cova P., P. PAgAno and M. PISAni, Domestic and international effects of the Eurosystem Expanded Asset Purchase Programme, IMF Economic Review, v. 67, 2, pp. 315-348, WP 1036 (October 2015).

ERColani V. and J. VAlle E AzEVEDo, How can the government spending multiplier be small at the zero lower bound?, Macroeconomic Dynamics, v. 23, 8. pp. 3457-2482, WP 1174 (April 2018).

FERrero G., M. Gross and S. NerI, On secular stagnation and low interest rates: demography matters, International Finance, v. 22, 3, pp. 262-278, WP 1137 (September 2017).

FoA G., L. Gambacorta, L. Guiso and P. E. Mistrulli, The supply side of household finance, Review of Financial Studies, v.32, 10, pp. 3762-3798, WP 1044 (November 2015).

Giordano C., M. MARINUCCI and A. Silvestrini, The macro determinants of firms' and households' investment: evidence from Italy, Economic Modelling, v. 78, pp. 118-133, WP 1167 (March 2018).

Gomellini M., D. Pellegrino and F. GifFoni, Human capital and urban growth in Italy,1981-2001, Review of Urban \& Regional Development Studies, v. 31, 2, pp. 77-101, WP 1127 (July 2017).

MAGRI S., Are lenders using risk-based pricing in the Italian consumer loan market? The effect of the 2008 crisis, Journal of Credit Risk, v. 15, 1, pp. 27-65, WP 1164 (January 2018).

MercatANTi A., T. MAKINEN and A. SiLVESTRINI, The role of financial factors for european corporate investment, Journal of International Money and Finance, v. 96, pp. 246-258, WP 1148 (October 2017).

Miglietta A., C. Picillo and M. Pietrunt, The impact of margin policies on the Italian repo market, The North American Journal of Economics and Finance, v. 50, WP 1028 (October 2015). 
MONTEFORTE L. and V. RAPONI, Short-term forecasts of economic activity: are fortnightly factors useful?, Journal of Forecasting, v. 38, 3, pp. 207-221, WP 1177 (June 2018).

Neri S. and A. NOTARPIETRO, Collateral constraints, the zero lower bound, and the debt-deflation mechanism, Economics Letters, v. 174, pp. 144-148, WP 1040 (November 2015).

PANCRAZI R. and M. PIETRUNTI, Natural expectations and home equity extraction, Journal of Housing Economics , v. 46, 4, WP 984 (November 2014).

PEREDA FERnANDEZ S., Teachers and cheaters. Just an anagram?, Journal of Human Capital, v. 13, 4, pp. 635-669, WP 1047 (January 2016).

RigGi M., Capital destruction, jobless recoveries, and the discipline device role of unemployment, Macroeconomic Dynamics, v. 23, 2, pp. 590-624, WP 871 (July 2012).

2020

Alessandri P. and M. Bottero, Bank lending in uncertain times, R European Economic Review, V. 128, WP 1109 (April 2017).

Antunes A. and V. Ercolani, Public debt expansions and the dynamics of the household borrowing constraint, Review of Economic Dynamics, v. 37, pp. 1-32, WP 1268 (March 2020).

ARDUINI T., E. PATACCHINI and E. RAINONE, Treatment effects with heterogeneous externalities, Journal of Business \& Economic Statistics, , v. 38, 4, pp. 826-838, WP 974 (October 2014).

BRIPI F., D. LOSCHIAVO and D. REVELLI, Services trade and credit frictions: evidence with matched bankfirm data, The World Economy, v. 43, 5, pp. 1216-1252, WP 1110 (April 2017).

BRONZINI R., G. CARAMELLINO and S. MAGRI, Venture capitalists at work: a Diff-in-Diff approach at latestages of the screening process, Journal of Business Venturing, v. 35, 3, WP 1131 (September 2017).

COIBION O., Y. GORODNICHENKO and T. ROPELE, Inflation expectations and firms' decisions: new causal evidence, Quarterly Journal of Economics, v. 135, 1, pp. 165-219, WP 1219 (April 2019).

CORSELlO F. and V. NISPI LANDI, Labor market and financial shocks: a time-varying analysis, Journal of Money, Credit and Banking, v. 52, 4, pp. 777-801, WP 1179 (June 2018).

COVA P. and F. NATOLI, The risk-taking channel of international financial flows, Journal of International Money and Finance, v. 102, WP 1152 (December 2017).

D'IGNAZIO A. and C. MENON, The causal effect of credit Guarantees for SMEs: evidence from Italy, The Scandinavian Journal of Economics, v. 122, 1, pp. 191-218, WP 900 (February 2013).

ERCOLANi V. and F. NATOLI, Forecasting US recessions: the role of economic uncertainty, Economics Letters, v. 193, WP 1299 (October 2020).

MAKINEN T., L. SARNO and G. ZINNA, Risky bank guarantees, Journal of Financial Economics, v. 136, 2, pp. 490522, WP 1232 (July 2019).

NisPi LANDI V., Capital controls spillovers, Journal of International Money and Finance, v. 109, WP 1184 (July 2018).

RAINONE E. and F. VACIRCA, Estimating the money market microstructure with negative and zero interest rates, Quantitative Finance, v. 20, 2, pp. 207-234, WP 1059 (March 2016).

RIZZICA L., Raising aspirations and higher education. Evidence from the UK's widening participation policy, Journal of Labor Economics, v. 38, 1, pp. 183-214, WP 1188 (September 2018).

SANTIONI, R., F. SCHIANTARELLI and P. STRAHAN, Internal capital markets in times of crisis: the benefit of group affiliation, Review of Finance, v. 24, 4, pp. 773-811, WP 1146 (October 2017).

SChiantarelli F., M. Stacchini and P. Strahan, Bank Quality, judicial efficiency and loan repayment delays in Italy, Journal of Finance, v. 75, 4, pp. 2139-2178, WP 1072 (July 2016).

\section{FORTHCOMING}

Albanese G., G. DE Blasio and A. LocAtelli, Does EU regional policy promote local TFP growth? Evidence from the Italian Mezzogiorno, Papers in Regional Science, WP 1253 (December 2019).

Baltrunaite A., C. Giorgiantonio, S. Mocetti and T. Orlando, Discretion and supplier selection in public procurement, Journal of Law, Economics, and Organization, WP 1178 (June 2018). 
Bologna P., A. Miglietta and A. Segura, Contagion in the CoCos market? A case study of two stress events, International Journal of Central Banking, WP 1201 (November 2018).

BotTERo M., F. MEZZANOTTI and S. LENZU, Sovereign debt exposure and the Bank Lending Channel: impact on credit supply and the real economy, Journal of International Economics, WP 1032 (October 2015).

BRONZINI R., S. MOCETTI and M. MONGARDINI, The economic effects of big events: evidence from the Great Jubilee 2000 in Rome, Journal of Regional Science, WP 1208 (February 2019).

COVA P., P. PAGANO, A. NOTARPIETRO and M. PISANI, Secular stagnation, R\&D, public investment and monetary policy: a global-model perspective, Macroeconomic Dynamics, WP 1156 (December 2017).

DEL PRETE S. and S. FEDERICO, Do links between banks matter for bilateral trade? Evidence from financial crises, Review of World Economics, WP 1217 (April 2019).

Fidora M., C. GIORDANO and M. SCHMITZ, Real exchange rate misalignments in the Euro Area, Open Economies Review, WP 1162 (January 2018).

Gerali A. and S. Neri, Natural rates across the Atlantic, Journal of Macroeconomics, WP 1140 (September 2017).

Li F., A. MercatAnti, T. MAKINEN and A. SiLVESTRINI, A regression discontinuity design for ordinal running variables: evaluating central bank purchases of corporate bonds, Annals of Applied Statistics, WP 1213 (March 2019).

LiberATI D. and M. LOBERTO, Taxation and housing markets with search frictions, Journal of Housing Economics, WP 1105 (March 2017).

Loschiavo D., Household debt and income inequality: evidence from Italian survey data, Review of Income and Wealth, WP 1095 (January 2017).

METELli L. and F. NATOLI, The international transmission of US tax shocks: a proxy-SVAR approach, IMF Economic Review, WP 1223 (June 2019).

Mocetti S., G. RomA and E. RubOLINO, Knocking on parents' doors: regulation and intergenerational mobility, Journal of Human Resources, WP 1182 (July 2018).

MOdENA F., E. RETTORE and G. M. TANZI, The effect of grants on university dropout rates: evidence from the Italian case, Journal of Human Capital, WP 1193 (September 2018).

NiSPI LANDI V. and A. SCHIAVONE, The effectiveness of capital controls, Open Economies Review, WP 1200 (November 2018).

Pereda Fernandez S., Copula-based random effects models for clustered data, Journal of Business \& Economic Statistics, WP 1092 (January 2017).

PERICOLI M., On risk factors of the stock-bond correlation, International Finance, WP 1198 (November 2018).

Pericoli M. and M. TABOGA, Nearly exact Bayesian estimation of non-linear no-arbitrage term-structure models, Journal of Financial Econometrics, WP 1189 (September 2018).

RAINONE E., The network nature of otc interest rates, Journal of Financial Markets, WP 1022 (July 2015). 